\title{
REDISTRIBUTION OR EDUCATION? The Political ECONOMY of THE Social Race
}

\author{
MICHELE BERNASCONI \\ PAOLA PROFETA
}

CESIFO WORKING PAPER NO. 1934

CATEgory 1: Public Finance

MARCH 2007

An electronic version of the paper may be downloaded

- from the SSRN website:

- from the RePEc website:

- from the CESifo website:

www.SSRN.com

Www.RePEc.org

www.CESifo-group.de 


\title{
REDISTRIBUTION OR EDUCATION? THE Political ECONOMY OF THE SOCIAL RACE
}

\begin{abstract}
In an overlapping generations model with two social classes, rich and poor, parents of the different social classes vote on two issues: redistributive policies for them and education investments for their kids. Public education is the engine for growth through its effect on human capital; but it is also the vehicle through which kids born from poor families may exchange their positions with kids born from rich families. This is because education reduces the probability of the mismatch, i.e. individuals with low talent but coming from rich families being placed in jobs which should be reserved to people with high talent (and vice-versa). We find a political economy equilibrium of the voting game using probabilistic voting. When the poor are more politically influent, the economy is characterized by a higher level of education, growth and social mobility than under political regimes supported by the rich; pretax inequality is greater in the first case, but post-tax is lower.
\end{abstract}

JEL Code: J62, J24, H10.

Keywords: social mobility, talents' mismatch, probabilistic voting.

"... For if the son of a golden or silver parent has an admixture of brass and iron, then nature orders a transposition of ranks, and the eye of the ruler must not be pitiful towards the child because he has to descend the scale and become a husbandman or artisan, just as there may be sons of artisans who having an admixture of gold or silver in them are raised to honour, and become guardians or auxiliaries. For an oracle says that when a man of brass or iron guards the State, it will be destroyed" [Plato, The Republic - Book III, 414 D, circa 360 BCE; translation by Benjamin Jowett, 1865].

Michele Bernasconi
Department of Economics
University of Insubria
Via Monte Generoso 71
21100 Varese
Italy
bernasconi@uninsubria.it

\author{
Paola Profeta \\ Institute of Political Economics \\ University "L. Bocconi" \\ Via Gobbi 5 \\ 20136 Milano \\ Italy \\ paola.profeta@uni-bocconi.it
}

We thank participants to SIEP 2006 Annual Meeting, Bocconi University seminar and to Vincenzo Galasso, John Hassler, Raffaello Seri and Guido Tabellini for useful comments. All errors are ours. Paola Profeta acknowledges support from CES during her visit in February 2007. 


\section{Introduction}

In a social race individuals of different social classes compete to improve their economic positions. The outcome of this competition depends on individual talent, individual and family behavior, and on public policies.

This paper analyzes the effects of two public transfer programs, redistribution and education, on the outcome of a social race between two social classes, the rich and the poor. In an intergenerational setting we explore the economic motivations and the political process leading parents to choose redistributive policies for them and public education programs for their kids.

On the conceptual side, the main contribution of the paper is to draw attention on the different strategic incentives that parents of different classes have in investing on the education of their kids. Education has always been considered an important input for economic growth especially for its effect on human capital. Here, we emphasize an additional, essential role of education: namely, education can increase social mobility. A crucial mechanism through which this effect can occur is that education reduces what we call the "mismatch of talents" in society.

Since Plato, a fundamental principle of political philosophy in western societies has been that, in an ideal social state, the allocation of individuals in social classes should be made according to talents. High talent individuals should be assigned to higher job positions and low talent individuals to more basic jobs and thus lower social classes. However, this perfect match does not always occur in societies, since social positions are often inherited through family lines to an extent which is difficult to explain only by factors such as genetic transmission of talent. This may first of all happen because talent is quite difficult to observe directly. Moreover, family connections, social relations, neighborhood networks may give more chances to kids from rich families of being allocated in better job positions, and hence of remaining rich, than to kids from poor families 1 . However, we also argue that this "mismatch of talents" is sensitive to public policies. Our main argument is that public education may increase the capacity of a society to correctly recognize the true talent of individuals, to allocate them to the correct social classes and, consequently, to increase social mobility.

In a model with imperfect information, we show that strategic behaviors to affect the social race emerge, due to this effect of public education on the mismatch of talents. The poor prefer high education spending to reduce the social mismatch and increase exchange mobility, while the rich prefer low education spending, provided that this will stop exchange mobility by maintaining a high mismatch of talents. More precisely, the rich trade-off a positive effect of education on growth with the (for them) negative effect on

\footnotetext{
${ }^{1}$ See e.g. Bowles and Gintis (2002) and the references therein for discussion of the various factors, genetic and environmental, entering in the causal mechanism of the intergenerational transmission of economic status.
} 
social mobility.

These strategic incentives are embedded in a probabilistic voting game, where the two social classes vote simultaneously over a pure redistributive taxation programme and a balanced public education budget. The political economy equilibrium depends on who, amongst the poor and the rich, have more political influence. When the poor are more politically influent, the economy is characterized by higher spending in education and lower spending in redistribution with respect to the case in which the two classes have the same political influence (neutral case). When instead the rich are more politically influent, there is lower spending in redistribution and in education with respect to the neutral case.

This economy shows an interesting dynamics. When the poor are more politically influent, growth and social mobility are larger, pre-tax inequality is greater, and post-tax inequality is lower than in the case where the rich are more politically influent. Interestingly, higher growth is associated with less mismatch and more mobility. This is due to two effects: first, there is an indirect effect, i.e. a society with fewer mismatches is associated with more education, which thus induces more human capital and growth. Second, when the mismatch of talents causes also an efficiency cost in production, a direct effect emerges, and higher growth is associated with fewer mismatches for any level of average human capital.

This paper introduces a new mechanism that relates class formation, public education and social mobility. Imperfect information on the "true" talent of individuals creates the mismatch between people talent and their allocation in social classes which may be reduced by public education, yet not by pure redistributive policies. To develop this story we introduce various new ingredients in the literature.

Firstly, imperfect information is a crucial ingredient to explain the existence of the mismatch of talents. We consider an overlapping generations model of human capital formation where, as in various previous studies (e.g. Becker and Tomes 1979, Loury 1981 and, more recently, Bénabou 1996), innate ability concurs with family and social backgrounds to determine the economic attainment of kids in the social race. However, unlike in these previous contributions, we explicitly model a genetic transmission of talent, using transition probabilities, which are assumed, together with talent, to be unobservable.

Secondly, the idea that public education promotes social mobility has also been considered by various previous literature (see e.g. reviews in Solon 1999, Breen and Jonsson 2005, Checchi 2006). In most of the previous contributions, however, the impact of public education on social mobility is due to capital market imperfections, which in a world where private education is possible, may prevent the poor from undertaking the same level of education investment as the rich (as in e.g. Becker and Tomes 1986, Maoz and Moav 1999, Restuccia and Urrutia 2004). We emphasize a different mechanism, 
based on the mismatch of talents, which is independent from capital market imperfections and from the role of private education. In our paper all education is public and there is no role for capital markets to play. Still, the level of public education affects social mobility, because it makes it easier for the "true" talent of individuals to be revealed" ${ }^{2}$. This new mechanism also crucially differentiates our contribution from some previous studies that focused on the effects of the allocation of individuals on social mobility and growth via technological changes, such as Galor and Tsiddon (1997) and Hassler and Mora (2000).

Thirdly, our paper builds a probabilistic voting model (see Lindbeck and Weibull 1987, and Persson and Tabellini 2000) to jointly determine two public policies, income redistribution and public education. The previous literature has generally studied these two policies separately ${ }^{3}$. An exception is a recent paper by Levy (2005), which however focuses on the generational conflict within the class of poor agents, with young poor preferring public education and old poor preferring income redistribution. The political equilibrium then arises from endogenous political coalitions, in which rich agents collude with either the poor young or the poor old to minimize the size of the government. In our paper, instead, kids' preferences are internalized in parents' preferences and thus there is no generational conflict.

The paper is also closely tied to the idea of social mobility as equality of opportunity, and contributes to the recent political economy literature on equality of opportunity and redistribution. Recent contributions (Bénabou and Ok 2001) have in particular emphasized the emergence of a trade-off between social mobility and redistribution: in socially mobile communities, since the poor have more chance of upward mobility, they may be induced not to support high levels of redistribution. As a result, the level of redistribution arising in a more mobile society is lower than the one arising in a less mobile society (Alesina and La Ferrara 2005). Other contributions have emphasized the role of individuals' perceptions of exchange mobility (see Piketty 1995). These intuitive relations remain valid in our context. However, they treat mobility as exogenous to the political process, while we

\footnotetext{
${ }^{2}$ This is also relevant to study societies both quite immobile and, yet, where the system of private education is very limited (see e.g. Checchi, Ichino, Rustichini 1999, for the typical case of Italy).

${ }^{3}$ See Bodway and Keen (2000) and Harns and Zink (2003) for recent surveys of the traditional political economy literature on redistributive taxation and the more recent contributions on public education as a form of in kind redistribution (from rich to poor in Glomm and Ravikumar 1998, from poor to rich in Fernández and Rogerson 1995, from old to young in Poterba 1998, Gradstein and Kaganovich 2004).

${ }^{4}$ See Shorrocks (1978) and Atkinson (1981) for classical papers on the connections between social mobility and various notions of equality of opportunity, Roemer (1998) for an interpretation which emphasizes the distinction between equality of "outcomes" and equality of "opportunity", Fields and Ok (1999) for a review of the literature on social mobility measurement
} 
emphasize that the determination of both redistribution and social mobility crucially depends on the political competition between different social classes. As a consequence, in our paper, redistribution, education, talents' mismatch, and social mobility are all endogenously determined in a process of democratic decision.

The paper is organized as follows. Section 2 presents the general features of the overlapping generations model. Section 3 explains the political institution governing the social race and provides the results on the political economy equilibrium of the voting game between the social classes. Section 4 studies the dynamics of the system. Section 5 considers additional efficiency costs of the talents mismatch. Section 6 concludes suggesting how the framework of the paper can be extended in various directions of future analyses. All proofs are in the appendix.

\section{The setting of the race}

In this section, we introduce an overlapping generations economy made up of a continuum of dynasties $i$, with unit measure $i=[0 ; 1]$. Individuals are heterogenous in their innate talent, which can be high or low. They live for two periods: in the first period young individuals accumulate human capital building on their innate talent; in the second period adult individuals receive an income, which depends on the social class they have been allocated to and take voting decisions. Each adult person becomes a parent and gives birth to one kid. He dies at the end of the second period. Notice that in this environment individuals take no economic, but only political decisions. In fact, individuals' human capital accumulation and allocation into social classes depends mainly on the level of public education, which is determined in the political environment. Moreover, there is imperfect information, since the innate talent is unobservable, even to each individual, and cannot be inferred from the economic outcome. In this section we present the fundamental features of the economic setting, while Section 3 describes the political decision.

\subsection{Individuals and social classes}

In every period, the society is divided into two social classes of equal size. Social classes correspond to job's types and hence incomes. Rich individuals of dynasty $i$ have a high-paid job and they receive income $y_{t, i}=y_{t}^{R}$, while poor individuals have a low-paid job and receive income $y_{t, i}=y_{t}^{P}$, where the subscript index $t$ with $t=0,1,2, \ldots$ identifies individuals born at time $t$, the subscript index $i$ identifies the specific dynasty $i$ and the superscript index $R$ or $P$ identifies the social class, rich or poor. Incomes and social classes will be endogenously determined (see Section 2.4). All parents are employed and there is no flexibility in the amount of working hours. 
The process of class transition from parents of generation $t$ to parents of generation $t+1$ is represented by the following social mobility matrix:

\begin{tabular}{|c|c|c|}
\hline & $y_{t+1}^{P}$ & $y_{t+1}^{R}$ \\
\hline$y_{t}^{P}$ & $\widetilde{p}_{t+1}$ & $1-\widetilde{p}_{t+1}$ \\
\hline$y_{t}^{R}$ & $1-\widetilde{p}_{t+1}$ & $\widetilde{p}_{t+1}$ \\
\hline
\end{tabular}

where $\widetilde{p}_{t+1} \in[0,1]$ is the fraction of parents and kids who belong to the same social class, and $\left(1-\widetilde{p}_{t+1}\right)$ is the fraction of those belonging to different social classes.

\subsection{Preferences and public policies}

We assume that only parents take political decisions. Hence, only parents' preferences will matter. Parents experience a warm-glow in ensuring their kids with an adequate level of human capital to start their second period of life (Glomm and Ravikumar 1992) ${ }^{5}$. Mainly, parents value $C_{t, i}$ in the second period of their life and their kids' level of human capital $h_{t+1, i}$ according to the following Cobb-Douglas utility function:

$$
V\left(C_{t, i}, h_{t+1, i}\right)=\ln \left(C_{t}, i\right)+E_{t, i} \ln \left(h_{t+1, i}\right)
$$

where $E_{t, i}$ is the expectation operator for a parent's belief about his kid talent. We explain how these beliefs are formed in Section 2.6.

There are no capital markets. Government imposes a proportional tax rate $\tau_{t}$ on income. Per-head tax proceeds at all times $t=0,1,2, \ldots$ are given by $\tau_{t} \bar{y}_{t}$, with $\bar{y}_{t}=0.5 y_{t}^{P}+0.5 y_{t}^{R}$ being the average gross income at time $t$. Tax proceeds can either finance a pure redistributive program or public education: let $\gamma_{t} \in[0,1]$ be the fraction of tax proceeds going into redistribution and $\left(1-\gamma_{t}\right)$ into education. The redistributive program provides a lump-sum transfer $b_{t}$ to parents of generation $t$; public education finances a per-head amount $e_{t}$ of education spending that will enter the human capital of each young individual of generation $t+1$ (kids), as specified below. All education is public and the overall government budget is balanced at every period $t$, so that $b_{t}=\gamma_{t} \tau_{t} \bar{y}_{t}$ and $e_{t}=\left(1-\gamma_{t}\right) \tau_{t} \bar{y}_{t}$.

Net resources available for the second period consumption of each parent of generation $t$ are thus $C_{t, i}=y_{t, i}\left(1-\tau_{t}\right)+b_{t}$.

\subsection{Human capitals and innate talent}

Individuals form their human capital $h_{t, i}$ in the first period of life. A fundamental variable is innate ability or talent. Innate talent is a random shock hitting all individuals at the moment of their birth. For each individual $i$ it can take a low value $A^{L}$, or a high value $A^{H}$. For the generation born at time

\footnotetext{
${ }^{5}$ See also Galor and Zeira (1993), Bénabou (2000), Cremer and Pestieau (2004).
} 
$t=0$, we assume that the two values, $A^{L}$ and $A^{H}$, have equal probability. Starting with generation $t=1$, we assume a genetic mechanism of talent transmission, which follows a simple Markov process: with probability $p$ an individual $i$ has the same talent of his parent and with probability $1-p$ he has the opposite talent. The law of large number holds, so that at all $t$ half individuals are born with $A^{L}$ and half with $A^{H}$.

Individuals form their human capitals according to a Cobb-Douglas learning technology, which builds on the average level of knowledge reached by the society in the previous generation (i.e. the existing stock of human capital), transmitted to the new born individuals through education. Formally, for any individual $i$ of generation $t+1$ and innate talent $A^{j}$ (where $A^{j}$ can either be $A^{L}$ or $A^{H}$ ), human capital is given by:

$$
h_{t+1, i}=e_{t}^{\xi} \bar{H}_{t}^{\delta} A^{j}
$$

where $\bar{H}_{t}$ is the average human capital at time $t ; e_{t}$ is the per-head level of public education decided by parents at time $t$ for their kids; and $\xi$ and $\delta$ are the parameters of the Cobb-Douglas, with both $\delta$ and $\xi \in(0,1)$.

Notice that at time $t=0$ society starts with no parents, thus the human capital accumulation for a young person with talent $A^{j}$ is some primitive knowledge $k_{0}$ directly available to all individuals ${ }^{6}$.

This process of human capital formation guarantees that at all $t=$ $0,1,2, \ldots$, there are only two types of human capital in the society: $h_{t+1}^{L}=$ $e_{t} \bar{H}_{t}^{\delta} A^{L}$ for all individuals with talent $A^{L}\left(h_{0}^{L}=k_{0} A^{L}\right.$ at $\left.t=0\right)$; and $h_{t+1}^{H}=e_{t}^{\xi} \bar{H}_{t}^{\delta} A^{H}$ for all individuals with $A^{H}\left(h_{0}^{H}=k_{0} A^{H}\right.$ at $\left.t=0\right)$. Further, since at all $t$ half individuals born with $A^{L}$ and half with $A^{H}$, both categories count for half of the population.

\subsection{Imperfect information and social mismatch}

An important feature of our setting is that we explicitly model the genetic transmission of talent, through the probability $p$. In this way we make explicit the possibility of an "objective" mechanism of genetic talent transmission. We assume, however, that the genetic probability $p$ of talent transmission is not generally known. Several authors have provided estimates that innate ability of a child is positively correlated with innate ability of

\footnotetext{
${ }^{6}$ Equation (3) is conceptually in line with the literature, in particular with the seminal work of Becker and Tomes (1979) and Loury (1981). These papers focus on human capital investment and innate ability as major sources of intergenerational earnings persistence. This idea is combined with a Cobb-Dogulas learning technology as in Glomm and Ravikumar (1992). However, differently from them, we include random ability, while neglecting kids' effort in the process of formation of human capital. Similar, more recent, contributions include Bénabou (1996), Fernández and Rogerson (1998), Davies, Zhang and Zeng (2005).
} 
the parent (see Bowles and Gintis 2002, Sacerdote 2002, Plug and Vijverberg 2003, and references therein), which implies that $p$ lies in some range of $(0.5,1)$. A complete agreement on the precise value of $p$ is however far from having being reached. This is because talent is very difficult to observe, even by the individuals themselves. Thus, we have an imperfect information context?.

If talents were perfectly observed, given the process of formation of human capital at equation (3) at all $t=0,1,2, \ldots$, it would be natural to assign high human capital individuals to high-paid jobs and viceversa. Assume for example that all jobs are paid according to the individual productivity measured by human capital. Thus, high human capital individuals would be rich, receiving income $y_{t}^{R}=h_{t}^{H}$, and low human capital individuals would be poor with income $y_{t}^{P}=h_{t}^{L}$. In this case the probability of class persistence of matrix (1) would always correspond to the probability of genetic talent transmission, that is $\widetilde{p}_{t+1}=p$. However, given imperfect information, this allocation process is unfeasible. In particular, social classes will be formed with some fundamental mismatch, i.e. people with high and low talents are mixed up in both classes of "poor" and "rich" 8 .

Precisely, we assume that at any time each social class contains a fraction $\bar{\alpha}_{t}$ of individuals allocated in the "correct" social class (low talented people in the class of poor, and high talented people in the class of rich) and a fraction $\left(1-\bar{\alpha}_{t}\right)$ of individuals allocated in the "wrong" social class. Thus, $\left(1-\bar{\alpha}_{t}\right)$ represents the "mismatch of talents". Formally, this means that for people born at $t+1$, the incomes of the rich and the poor are respectively given by:

$$
\begin{aligned}
y_{t+1}^{P} & =\bar{\alpha}_{t+1}\left(e_{t} \xi \bar{H}_{t}^{\delta} A^{L}\right)+\left(1-\bar{\alpha}_{t+1}\right)\left(e_{t} \xi \bar{H}_{t}^{\delta} A^{H}\right) \\
y_{t+1}^{R} & =\bar{\alpha}_{t+1}\left(e_{t} \xi \bar{H}_{t}^{\delta} A^{H}\right)+\left(1-\bar{\alpha}_{t+1}\right)\left(e_{t} \bar{H}_{t}^{\delta} A^{L}\right)
\end{aligned}
$$

\footnotetext{
${ }^{7}$ In particular, the hypothesis of imperfect information implies that talent cannot be observed either directly through the individual's human capital, or even indirectly through the individual's productivity. Suppose, for example, that each individual $i$ of generation $t+1$ produces an output $q_{t+1, i}$ according to the production function:

$$
q_{t+1, i}=h_{t+1, i}+\varepsilon_{t+1, i}
$$

where $h_{t+1, i}$ is the human capital of the individual, and $\varepsilon_{t+1, i}$ is an unobservable random shock in production (with $E\left(\varepsilon_{t+1, i}\right)=0$ ). Since there are only two types of human capitals, an individual with talent $A^{H}$ will produce $q_{t+1, i}=e_{t} \bar{H}_{t}^{\delta} A^{H}+\varepsilon_{t+1, i}$; while an individual with talent $A^{L}$ will produce $q_{t+1, i}=e_{t} \bar{H}_{t}^{\delta} A^{L}+\varepsilon_{t+1, i}$. Thus, equation (4) implies that if talent cannot be directly recognized from human capital, given the white noise $\varepsilon_{t+1, i}$, it cannot either be perfectly known from $q_{t+1, i}$.

${ }^{8}$ Other papers have studied the role of imperfect information on innate talent (e.g. Maoz and Moav 1999, Checchi, Ichino and Rustichini 1999). In these studies, however, uncertainty is completely resolved with the acquisition of education (for at least those individuals who acquire it). In our paper, instead, some uncertainty about innate talent remains even after education causing the mismatch.
} 
For individuals born at $t=0$, the two incomes are: $y_{0}^{P}=\bar{\alpha}_{0} k_{0} A^{L}+(1-$ $\left.\bar{\alpha}_{0}\right) k_{0} A^{H}$ and $y_{0}^{R}=\bar{\alpha}_{0} k_{0} A^{H}+\left(1-\bar{\alpha}_{0}\right) k_{0} A^{L}$.

Fig. 1 shows how the mismatch between people talent and social classes can arise in society9. Each individual is assigned to a social class according to an allocation mechanism which, for all $t=1, \ldots$, is based on two simple rules 10: i) a low talent kid with poor parents is always assigned to the class of poor and a high talent kid with rich parents to the class of rich; ii) a high talent kid with poor parents is assigned with probability $\alpha_{t+1}$ to the class of rich and with probability $\left(1-\alpha_{t+1}\right)$ to the class of poor, and a low talent kid with rich parents is assigned with probability $\alpha_{t+1}$ to the class of poor and with probability $\left(1-\alpha_{t+1}\right)$ to the class of rich. In other words, $\alpha_{t+1}$ is the probability that the society correctly recognizes the talents of individuals who should be assigned to a different class than their parents'; while $\left(1-\alpha_{t+1}\right)$ is the probability of having mistakes or errors in the allocation of these individuals.

This process of class formation suggests that, while in general there are little problems in putting both poor kids with low talent in the lower class and rich kids with high talent in the upper class 11 , it is more difficult to upgrade kids with high talents from poor parents and to downgrade kids from rich parents but with low talent 12 .

The process of class formation hence depends crucially on the probability $\alpha_{t+1}$. In the next section we will assume that $\alpha_{t}$ is endogenously determined based on the level of public education in the society, and we will discuss various factors which may affect $\alpha_{t+1}$. Thus, social classes will also be endogenously determined. Notice now that $\alpha_{t+1}$ enters both the determination of the fraction $\bar{\alpha}_{t+1}$ of people with the correct talent in each social class and the probability of class persistence $\widetilde{p}_{t+1}$ in society. Iterating from the example of Fig. 1 with $t=1$, the precise proportion $\bar{\alpha}_{t+1}$ follows this

\footnotetext{
${ }^{9}$ From equations (5) and (6) also notice that an incentive compatibility constraint in society requires that $y_{t+1}^{R}>y_{t+1}^{P}$, i.e. that $\bar{\alpha}_{t+1}>0.5$. In the next section we give the condition for this constraint to be satisfied.

${ }^{10}$ For the first generation born at $t=0$ the fractions $\bar{\alpha}_{0}$ and $\left(1-\bar{\alpha}_{0}\right)$ of people allocated respectively in the right and in the wrong social classes are determined randomly, with $\bar{\alpha}_{0}$ representing the initial condition of the system.

${ }^{11}$ Still, the setting can be easily generalized to include random errors even for the allocation of low-talented kids born from poor parents and high-talented kids born from rich parents.

${ }^{12}$ Given that social classes correspond to jobs' types, the allocation process of individuals in social classes may replicate quite realistic stories. For example, kids of a rich family have better opportunities to find an initial better-paid job (say, a stage), independently on their talent, because of family background, social connections, neighborhood networks etc. Their on-the-job performance may then reveal the true talent of this person. If he has a high talent, it is reasonable that he will keep the job, while if he has a low talent, with probability $\alpha_{t+1}$ he is recognized and he has to quit. Instead, the kids of a poor family are on their own. Low talent kids will mainly find a low-paid job. Yet, if they have high talent, with (the same) probability $\alpha_{t+1}$, they may be recognized and upgraded to high-paid jobs.
} 
Figure 1: The formation of social classes with the mismatch of talents

Poor

Rich

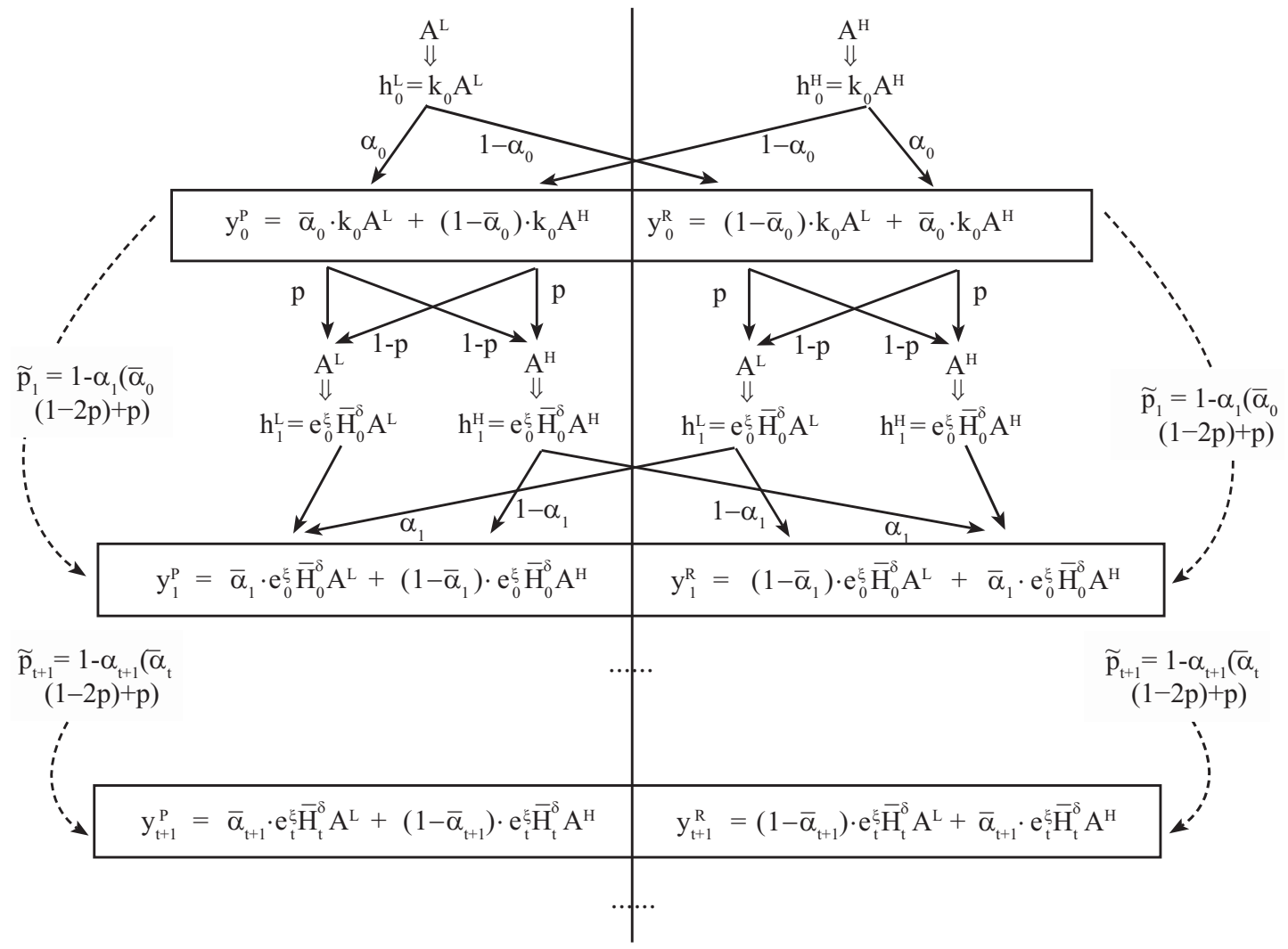

law of motion:

$$
\bar{\alpha}_{t+1}=1+\left[\bar{\alpha}_{t}(2 p-1)-p\right]\left(1-\alpha_{t+1}\right)
$$

Similarly, in the society the probability of class persistence $\widetilde{p}_{t+1}$ for kids of poor parents to remain poor and for kids of rich parents to remain rich evolves according to the following equation (see dotted lines in Fig. 1):

$$
\widetilde{p}_{t+1}=1-\alpha_{t+1}\left(\bar{\alpha}_{t}(1-2 p)+p\right)
$$

The latter equation shows that $\widetilde{p}_{t+1}$ is equal to $p$ only when both $\alpha_{t+1}$ and $\bar{\alpha}_{t}$ are 1 ; while $\widetilde{p}_{t+1}>p$ whenever either $\alpha_{t+1}$ or $\bar{\alpha}_{t}$ (or both) are less than 1 . Thus, when imperfect information generates a mismatch of talents, class persistence is greater than what should be justified by the genetic probability of talent transmission. 


\subsection{Education and class transitions}

In this section we argue that the probability $\alpha_{t+1}$ of correctly recognizing individuals' talents is affected by the level of public education. A society with a higher level of education is more able to correctly allocate individuals in their appropriate job or social class. In particular, although family background, social connections, neighborhood networks and all similar factors still remain at the origin of the social mismatch illustrated in Fig. 1, education better allows the society to disentangle the impact of family background from innative talent. Education thus increases the equality of opportunity, as explained by several studies (see e.g. Checchi 2006, and references therein). Yet, the ability of the society to separate these two effects, family background and innate talent, may be reduced by the size of the group of individuals (low talent kids from rich parents and high talent kids from poor parents) who has to be evaluated.

Formally, we assume the following relation:

$$
\alpha_{t+1}=\frac{1-c+d \frac{e_{t}}{\bar{y}_{t}}}{\left(1-\bar{\alpha}_{t}\right) p+\bar{\alpha}_{t}(1-p)}
$$

where $1-c$ represents the general degree of openness in society, that is the extent to which society offers equal chances to all individuals independently of the level of public education; the parameter $d$ is the degree to which openness responds to the per-head education expenditure ${ }^{13}$; and the denominator expresses for each social class the number of kids at time $t+1$ who, if correctly allocated according to their talent, should change their social position with respect to that of their parents. Equation (9) assumes that the capacity of education of increasing the correct allocation of talents is lower the higher the number of people who should change their social class with respect to that of their parents. This is because the signaling of talents through education works better in a small group.

We generally expect $c$ greater than 0.5 (and lower than 1) and $d \in$ $(0,0.5)$. We also assume that the following condition is satisfied:

$$
c-d \geq p .
$$

Condition (10) in particular guarantees that $\alpha_{t+1}$ is a genuine probability belonging to the interval $(0,1)$ at all $t$. Specifically, when $\frac{e_{t}}{\bar{y}_{t}}=0$ and $c=1$, society is completely closed and immobile $\left(\alpha_{t+1}=0\right.$ and $\widetilde{p}_{t+1}=1$; see equation 8); when instead $\frac{e_{t}}{\bar{y}_{t}}=1$ and $c-d=p$, the numerator of (9) reaches its maximum value $1-p$, which is also the lower bound of the denominator, when in particular $\bar{\alpha}_{t}=1$.

\footnotetext{
${ }^{13}$ Also notice that although in this paper we only consider the effect of public education on the mismatch of talents and mobility, expression (9) can be easily extended to include the impact of other factors and public policies, amongst which health, security, or liberalization policies.
} 
More specifically, using equation (9), both the proportion of individuals correctly allocated in the society $\bar{\alpha}_{t+1}$ (equation 7 ) and the probability of class persistence $\widetilde{p}_{t+1}$ (equation 8 ), can be recomputed as follows:

$$
\bar{\alpha}_{t+1}=2-\left(c-d \frac{e_{t}}{\bar{y}_{t}}\right)-p+\bar{\alpha}_{t}(2 p-1)
$$

and

$$
\widetilde{p}_{t+1}=c-d \frac{e_{t}}{\bar{y}_{t}}
$$

Equations (11) and (12) deserve some comments. Equation (11) describes how the mismatch evolves in the society at any time $t>0$ (starting from some initial condition $\bar{\alpha}_{0}$ ). It also shows that condition (10) is necessary and sufficient for $\bar{\alpha}_{t+1} \in[0.5,1]$ at all $t$, that is for society to respect the incentive compatibility constraint $y_{t+1}^{P}<y_{t+1}^{R}$ at all $t=0,1,2, \ldots$ (see footnote 9 ). Furthermore, it is worthwhile noticing that, for some time-invariant $\frac{e_{t}}{\bar{y}_{t}} \in[0,1]$, equation (11) implies a unique steady state $\bar{\alpha}_{v}$, obtained as:

$$
\bar{\alpha}_{v}=\frac{2-\left(c-d \frac{e_{t}}{\bar{y}_{t}}\right)-p}{2(1-p)} .
$$

The latter entails $\bar{\alpha}_{v}=1$, namely that society can end-up in a state without mismatch, if and only if $c-d=p$ and $\frac{e_{t}}{\bar{y}_{t}}=1.14$

Equation (12) is crucial in what follows: it makes clear that public education increases exchange mobility, by reducing the mismatch of talents. It also shows that while in our model ability may be genetically transmitted, the genetic probability $p$ of talent transmission plays no role in the mechanism of inheritance of economic inequality ${ }^{15}$. Moreover, in the present world of imperfect information, it represents the only relationships that individuals can observe, as explained in the following section.

\subsection{Individuals' information set}

Remember that, according to their preferences at equation (2), parents care about their kids' human capital and hence about the position that their kids will have in the society. Although parents do not observe their kids' talents nor the genetic probability $p$ of talent transmission, they have information on the ex-post realizations of $\widetilde{p}_{t}$ and $e_{t}$. In other words, although individuals do not know all the process leading to equation (12), they may use it to form beliefs about the likelihoods that their kids will go ahead in society.

\footnotetext{
${ }^{14}$ Convergence is monotonic with an increasing trajectory if $\bar{\alpha}_{v}>\bar{\alpha}_{0}$ and a decreasing trajectory if $\bar{\alpha}_{0}>\bar{\alpha}_{v}$.

${ }^{15}$ This result is indeed consistent with various empirical evidence (see e.g. Bowles and Gintis 2002, in particular their section on "the role of genetic inheritance of cognitive skill", pp. 10-13).
} 
In particular, a poor parent will assign probability $\widetilde{p}_{t+1}$, as defined in equation (12), that his kid will be recognized by the society to have low human capital $e_{t}^{\xi} \bar{H}_{t}^{\delta} A^{L}$, and will assign probability $\left(1-\widetilde{p}_{t+1}\right)$ that he will be recognized to have high human capital $e_{t} \xi \bar{H}_{t}^{\delta} A^{H}$; the converse holds for the rich. Using this hypothesis in equation (2), the utility functions for the poor and the rich parents become, respectively:

$$
\begin{aligned}
& V\left(C_{t}^{P}, h_{t+1}^{j}\right)=\ln \left(C_{t}^{P}\right)+\widetilde{p}_{t+1} \ln \left(e_{t}^{\xi} \bar{H}_{t}^{\delta} A^{L}\right)+\left(1-\widetilde{p}_{t+1}\right) \ln \left(e_{t}^{\xi} \bar{H}_{t}^{\delta} A^{H}\right) \\
& V\left(C_{t}^{R}, h_{t+1}^{j}\right)=\ln \left(C_{t}^{R}\right)+\widetilde{p}_{t+1} \ln \left(e_{t}^{\xi} \bar{H}_{t}^{\delta} A^{H}\right)+\left(1-\widetilde{p}_{t+1}\right) \ln \left(e_{t} \xi \bar{H}_{t}^{\delta} A^{L}\right)
\end{aligned}
$$

These equations show two critical effects of education: on the one side, it increases human capital accumulation for all individuals, and hence growth; on the other side, it introduces a strategic dimension in the social race. In fact, the poor have an incentive to prefer more public education to increase the chance for their kids to have a recognized high talent and become rich, while the rich have the opposite incentive to reduce public education to avoid that kids with poor parents will have recognized a high talent and take the good jobs at their place. In the remaining of the paper we will show how this strategic dimension of public education can affect substantially the political behavior of the two social classes and its consequences for the macroeconomy.

\section{The political institution}

At time $t$, based on their preferences at equations (14) and (15), poor and rich parents vote on both the overall tax rate $\tau_{t}$ and on the fraction $\gamma_{t}$ of tax proceeds going into pure redistribution $b_{t}=\gamma_{t} \tau_{t} \bar{y}_{t}$ (with the fraction $\left(1-\gamma_{t}\right)$ financing the per-head public education expenditure $\left.e_{t}=\left(1-\gamma_{t}\right) \tau_{t} \bar{y}_{t}\right)$.

In this section we introduce a probabilistic voting model to determine the equilibrium levels of $\tau_{t}$ and $\gamma_{t}$. These will determine the GDP shares going into redistribution and public education, i.e. the ratios $\frac{b_{t}}{\bar{y}_{t}}=\gamma_{t} \tau_{t}$ and $\frac{e_{t}}{\bar{y}_{t}}=\left(1-\gamma_{t}\right) \tau_{t}$, respectively. In Section 4 we will analyze the dynamics of the model and the evolution of incomes growth, inequality and social mobility.

\subsection{The political economy equilibrium}

In the political economy literature, models of probabilistic voting (in the tradition of Lindbeck and Weibull 1987, building in turn on Coughlin and Nitzan 1981a and 1981b), are used to solve for political equilibria in situations in which political platforms include more than one issue 16 .

\footnotetext{
${ }^{16}$ See Persson and Tabellini (2000) for alternative solutions to political economy models involving multiple issues. Probabilistic voting is particularly appropriate in our context, because it allows dealing with "ideological" components, which will differentiate the political influence of the two competing social classes, rich and poor.
} 
Consider two parties, or candidates. Before the election takes place, the parties commit to a policy platform. They act simultaneously and do not cooperate. Each party chooses the platform which maximizes its expected number of votes, or, equivalently, the probability of winning the election. Platforms are chosen when the election outcome is still uncertain. The two parties differ along some other dimension relevant to the voters than the announced policies, unrelated to the policies at issue, and which may reflect ideological elements. Ideology may also twist voters' preferences away from strict economic interest. In particular, when there is an ideological twist, it pays candidates to propose policy mix more attractive to more mobile voters, also called the "swing" voters 17 .

As a general result of probabilistic voting models, there is a unique political equilibrium in which the two candidates propose the same policy. This policy maximizes a social welfare function weighting all voters' utility, with weights depending on the size of the "swing" voters in each class. If the number of swing voters is the same, all groups get equal weight in the candidate's decision, which turns out to be maximizing the average voters' utility. However, if the groups differ in how easily their votes can be swayed, the group containing more swing voters is more responsive to policy and gets a higher weight in the party's objective.

In our set-up, there are only two classes, the poor and the rich, with utility functions given in equations (14) and (15), respectively. Let $\omega_{t} \in$ $(0,+\infty)$ denote the weight measuring the proportion of "swing" voters in the class of "rich" relative to the proportion of "swing" voters in the class of "poor".

Definition. A probabilistic voting equilibrium at time $t$ is a pair $\left(\tau_{t}, \gamma_{t}\right)$ for $\tau_{t} \in[0,1]$ and $\gamma_{t} \in[0,1]$, which maximizes a policy maker's objective function given by:

$$
\begin{array}{r}
\max _{\gamma_{t}, \tau_{t}} W=\omega_{t}\left[\ln \left(C_{t}^{P}\right)+\widetilde{p}_{t+1} \ln \left(e_{t}^{\xi} \bar{H}_{t}^{\delta} A^{L}\right)+\left(1-\widetilde{p}_{t+1}\right) \ln \left(e_{t}^{\xi} \bar{H}_{t}^{\delta} A^{H}\right)\right] \\
+\ln \left(C_{t}^{R}\right)+\widetilde{p}_{t+1} \ln \left(e_{t}^{\xi} \bar{H}_{t}^{\delta} A^{H}\right)+\left(1-\widetilde{p}_{t+1}\right) \ln \left(e_{t}^{\xi} \bar{H}_{t}^{\delta} A^{L}\right)
\end{array}
$$

where: i) $\omega_{t}>0$; ii) $C_{t}^{i}=y_{t}^{i}\left(1-\tau_{t}\right)+\gamma_{t} \tau_{t} \bar{y}_{t}$ for $i=R, P$; iii $\tilde{p}_{t+1}=c-d \cdot \frac{e_{t}}{\bar{y}_{t}}$, with $e_{t}=\left(1-\gamma_{t}\right) \tau_{t} \bar{y}_{t}$ and $\bar{y}_{t}=0.5\left(y_{t}^{P}+y_{t}^{R}\right)$; iv $)$ and with $y_{t}^{P}, y_{t}^{R}, \bar{H}_{t}$ all given at time $t$.

Given the definition, when $\omega_{t} \in(0,1)$ the bias due to "swing" voters is in favor of the policy mix preferred by the rich; when $\omega_{t} \in(1,+\infty)$ the bias is in favor of the policy mix preferred by the poor; while when it is exactly $\omega_{t}=1$, there is no ideological bias and all preferences count equally.

\footnotetext{
17 "Swing" voters are more ideologically "neutral" individuals, whose vote can be more easily swayed by a policy change in their favor.
} 
The following proposition characterizes the political economy equilibrium under these three different political conditions.

Proposition 1 In the above economy, depending on $\omega_{t}$, the political equilibria are as follow:

- For $\omega_{t}=1$ (all voters count equally), $\tau_{t}=1$ and $\gamma_{t}=\frac{1}{1+\xi}$. Hence, the $G D P$ shares going into pure redistribution and into public education are, in the order: $\tau_{t} \gamma_{t}=\frac{1}{1+\xi}$ and $\tau_{t}\left(1-\gamma_{t}\right)=\frac{\xi}{1+\xi}$ at all $t=0,1,2, \ldots$;

- For $\omega_{t}>1$ (bias favors poor), $\tau_{t}=1$ and $\gamma_{t}<\frac{1}{1+\xi}$ for all $t=0,1,2, \ldots$. Hence, the GDP shares are: $\tau_{t} \gamma_{t}<\frac{1}{1+\xi}$ and $\tau_{t}\left(1-\gamma_{t}\right)>\frac{\xi}{1+\xi}$ at all $t=0,1,2, \ldots$; further, for a time-invariant $\omega_{t}$ (that is, constant for all $t=0,1,2, \ldots), \gamma_{t}$ is time-invariant, so that the two shares are also time-invariant;

- For $\omega_{t}<1$ (bias favors rich), $\tau_{t}$ and $\gamma_{t}$ are elaborate functions of the parameters (their exact values are given in Appendix); the more interesting GDP shares are: $\gamma_{t} \tau_{t}<\frac{1}{1+\xi}$ all $t=0,1,2, \ldots$ with $\gamma_{t} \tau_{t}=0$ for any $\omega_{t} \leq \frac{y_{t}^{P}}{y_{t}^{R}}$ and with $\frac{\partial \gamma_{t} \tau_{t}}{\partial\left(y_{t}^{P} / y_{t}^{R}\right)}>0$ when $\omega_{t} \in\left(\frac{y_{t}^{P}}{y_{t}^{R}}, 1\right) ;\left(1-\gamma_{t}\right) \tau_{t}<$ $\frac{\xi}{1+\xi}$ at all $t=0,1,2, \ldots ;$ further, for a time-invariant $\omega_{t},\left(1-\gamma_{t}\right) \tau_{t}$ is time-invariant.

Moreover, the shares of GDP going into redistribution $\gamma_{t} \tau_{t}$ and into public expenditure $\tau_{t}\left(1-\gamma_{t}\right)$, as functions of the various parameters of the political decision problem are characterized as depicted in Fig. 2, which is integral part of the Proposition.

The Proposition delivers the political economy equilibrium, as illustrated in Fig. 2. When $\omega=1$ there is no political bias towards any of the two social classes and the policy maker optimally chooses between education and redistribution ignoring any effect of education on social mobility. This is because a neutral policy maker is not interested in "who is who" in the social parade, i.e. he is utilitarian. Thus, he maximizes the objective function imposing the maximum tax rate $(\tau=1)$ and equalizes the marginal utility of all individuals 18 .

When $\omega \neq 1$ and education has a positive impact on exchange mobility $(d>0)$, the share of GDP going into public education increases with

\footnotetext{
${ }^{18}$ In fact, when $\omega=1$, the policy maker's objective function (16) reduces to $W=$ $\ln \left(C_{t}^{P}\right)+\ln \left(C_{t}^{R}\right)+\ln \left(e_{t}^{\xi} \bar{H}_{t}^{\delta} A^{L}\right)+\ln \left(e_{t}^{\xi} \bar{H}_{t}^{\delta} A^{H}\right)$. Its maximization then requires to equalize the marginal utilities of all individuals: rich and poor parents, high and low talent's kids. To do this, the policy maker divides the revenues collected so that the marginal benefit of one more unit of taxes spent for consumption today, that is $\frac{1}{\gamma}$, equals the marginal benefit of one more unit of taxes spent for education tomorrow, $\frac{\xi}{1-\gamma}$. Solving for $\gamma$, we have $\gamma=\frac{1}{1+\xi}$ and the GDP shares for redistribution and education are shown in Fig. 2 .
} 


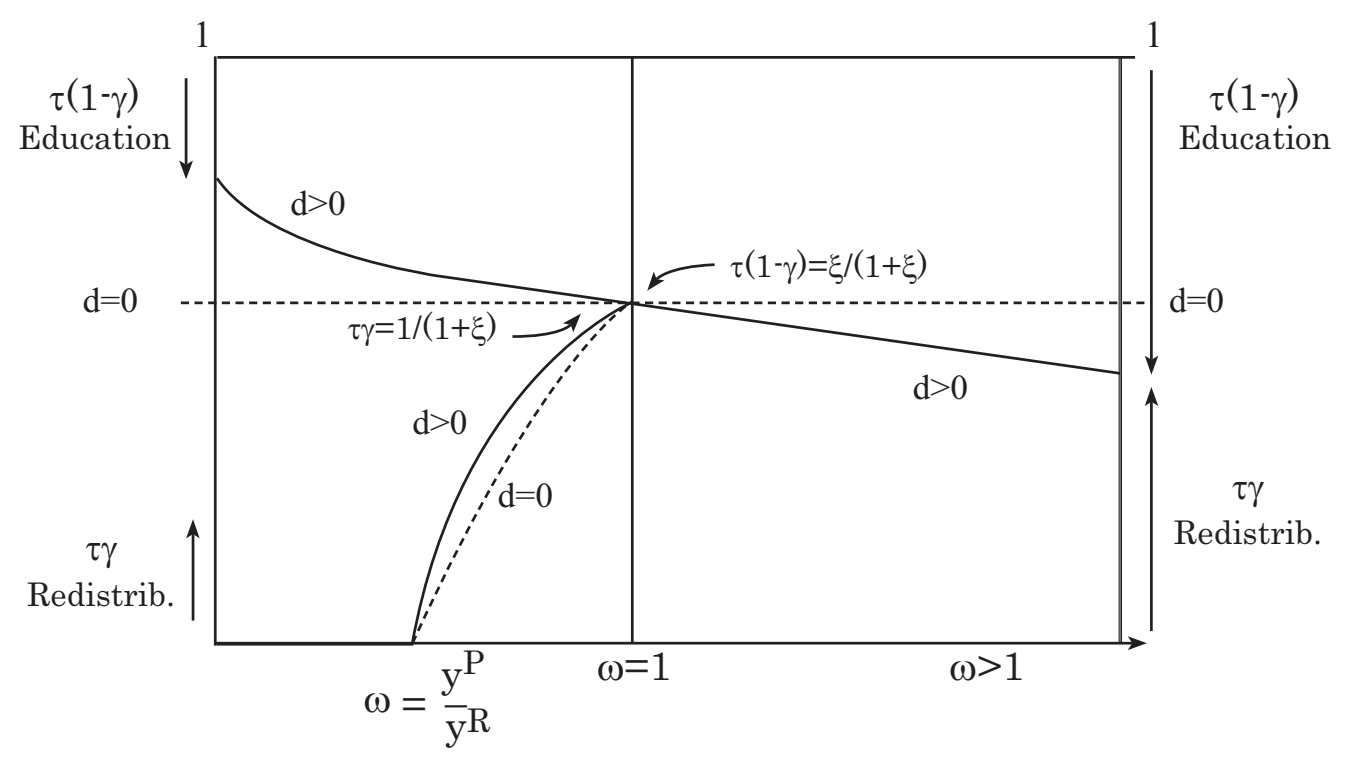

Figure 2: Political equilibrium for education and redistribution

$\omega \in(0,+\infty)$, meaning that when the poor have more political influence, education spending is larger than when the two social classes have equal influence, which in turn is larger than the case in which the rich have more political influence. Redistribution instead is zero if the rich have a very high political influence $\left(\omega_{t}<\frac{y_{t}^{P}}{y_{t}^{R}}\right)$; it turns positive and increases with $\omega$ when the rich trade-off more redistribution with less education, in their attempt to stop social mobility; and then decreases with $\omega$ when the poor have more political influence, since they prefer to increase education.

If instead education would play no role on exchange mobility $(d=0$, dotted lines in the figure), the incentive effects driven by social mobility, that induce the poor to prefer more education and the rich less, would obviously disappear, and education would not depend on $\omega$. Interestingly, in this case, a government under the political influence of the rich would reduce the level of redistribution with respect to the case when $d>0$. This is because, with the same tax revenues, the rich prefer now to spend more for public education and less for redistribution, since the effect of public education that they dislike has disappeared. On the other hand, redistribution would be maximum for $\omega \geq 1$, because when the poor have more political influence, they have no incentive to choose less redistribution in exchange of more education and mobility.

Notice also that, for time-invariant $\omega_{t}$, the equilibrium GDP share going into public education does not depend on time. This follows from the property of the Cobb-Douglas utility function and from the fact that both the rich and poor would in any case put a positive amount of resources 
in public education, for its positive effects on human capital. This important property of the equilibrium policy will be useful in the next section on the dynamics. Conversely, when the rich have more political influence and the policy maker spends some positive amount in redistribution (only when $\left.\omega_{t} \geq \frac{y_{t}^{P}}{y_{t}^{R}}\right)$, the GDP share of redistribution may change when $\frac{y_{t}^{P}}{y_{t}^{R}}$ is changing, in particular it increases when there is more pre-tax inequality, even for a constant $\omega_{t}$.

In the conclusions we will consider some possible extensions of the setting underlying Proposition 1, among which private education, the effects of different parents' beliefs about their kids' talents, and distortionary taxation.

\section{The dynamics of the economy}

This section compares the dynamics of all major endogenous variables of the system, for political regimes parametrized by the same $\omega_{t}$ of Proposition 1 . We focus on economic growth, measured by the changes in per-capita income $\bar{y}_{t+1}=0.5 y_{t+1}^{P}+0.5 y_{t+1}^{R}$; pre-tax inequality, measured by the difference between the two gross incomes ${ }^{19} I_{t+1}=\left(y_{t+1}^{R}-y_{t+1}^{P}\right)$; and social mobility, measured by $\left(1-\widetilde{p}_{t+1}\right)$. We also look at the evolution of the mismatch in society, as parametrized by the dynamics of $\bar{\alpha}_{t+1}$.

We study the dynamics of the system for the three time-invariant political conditions of $\omega_{t}: \omega^{N}=1$ when rich and poor have the same political influence (neutral regime), $\omega^{P}>1$, when the political bias favors the poor, and $\omega^{R}<1$ when the bias favors the rich. To identify the various macroeconomic variables under the three conditions, we will use the capital index $J=N, P, R$ in the obvious way ${ }^{20}$.

\subsection{Growth}

In this economy the average income, $\bar{y}_{t+1}=0.5 e_{t} \xi \bar{H}_{t}^{\delta}\left(A^{L}+A^{H}\right)$, is equal to average human capital in society, $\bar{y}_{t+1}=\bar{H}_{t+1}$. Thus, by substitution we obtain the following dynamics equation for average income ${ }^{21}$ :

$$
\bar{y}_{t+1}=0.5 e_{t} \bar{y}_{t}^{\delta}\left(A^{L}+A^{H}\right)
$$

Using now the results of Proposition 1, we can establish the following implications for economic growth under the three regimes $J=N, P, R$.

\footnotetext{
${ }^{19}$ Since in our economy for all $t$ half of the population is poor and half is rich, the only source of inequality is given by the difference of the two levels of incomes.

${ }^{20}$ This new index only applies to macroeconomic variables: for example, average income is $\bar{y}_{t+1}^{N}$ when $\omega=\omega^{N}, \bar{y}_{t+1}^{P}$ when $\omega=\omega^{P}$, and $\bar{y}_{t+1}^{R}$ when $\omega=\omega^{R}$. Since we do not need to identify micro variables, such as individual income, under different political regimes, we will continue to use $y_{t+1}^{P}$ and $y_{t+1}^{R}$ to indicate the income of the two social classes, poor and rich respectively, independently of the political regime.

${ }^{21}$ Notice that $\bar{y}_{t+1}$ does not depend on $\bar{\alpha}_{t+1}$, i.e. the mismatch does not affect growth. In a different specification in Section 5 we will include the cost of the mismatch.
} 
Proposition 2. Given a fixed initial condition for the average income $\bar{y}_{0}=0.5 k_{0}\left(A^{L}+A^{H}\right)$ equal for all $J=N, P, R$, and given time-invariant $\omega^{J}$ under regimes $J=N, P, R$, economic growth evolves according to:

$$
\bar{y}_{t+1}^{J}=B^{J}\left(\bar{y}_{t}^{J}\right)^{\xi+\delta}
$$

where $B^{J}=0.5\left(A^{L}+A^{H}\right)\left[\left(1-\gamma^{J}\right) \tau^{J}\right]^{\xi}$, constant under all $J$, and with $B^{P}>B^{N}>B^{R}$. Thus, $\bar{y}_{t+1}^{P}>\bar{y}_{t+1}^{N}>\bar{y}_{t+1}^{R}$ for all $t=0,1,2, \ldots$.

Equation (18) is virtually identical to that studied by Glomm and Ravikumar (1992)22. Growth depends on the sum $\xi+\delta$. We can distinguish three cases under which comparing the different political regimes (see Fig. 3): a) if $\xi+\delta<1$, under all political conditions there are unique, globally stable, steady states with $\bar{y}_{s}^{P}>\bar{y}_{s}^{N}>\bar{y}_{s}^{R}>0$. Notice also that in this case $\lim _{t \rightarrow \infty} \bar{y}_{t+1}^{J} / \bar{y}_{t}^{J}=1$ for all $\left.J ; b\right)$ if $\xi+\delta=1$, there is no steady state under the regime $J=N, P, R$ for which $B^{J} \neq 1$. In this case $\left.\bar{y}_{t+1}^{J} / \bar{y}_{t}^{J}=B^{J} ; c\right)$ if $\xi+\delta>1$, under all political conditions there are unique unstable steady states with $\bar{y}_{s}^{R}>\bar{y}_{s}^{N}>\bar{y}_{s}^{P}>0$. In this case $\bar{y}_{t+1}^{J} / \bar{y}_{t}^{J}>1$ and $\bar{y}_{t+1}^{J} / \bar{y}_{t}^{J}$ increases over time if $\bar{y}_{0}>\bar{y}_{s}^{J}, 23$

Thus, as in Glomm and Ravikumar (1992), education busts growth through its impact on human capital, so that economic growth is higher when education is higher. However, since the strategic effect of education on social mobility induces the poor to support education more than the rich, political regimes supported by the poor are also more effective to sustain economic growth. In fact, in case $a$ ) the long-run growth rates are zero under all political regimes, while in cases $b$ ) and $c$ ) the highest long-run growth rate is when the poor have more political influence, followed by the neutral case and then by the situation in which the rich have more influence.

\subsection{Inequality}

Pre-tax inequality is measured by the difference $I_{t+1}^{J}=\left(y_{t+1}^{R}-y_{t+1}^{P}\right)$ which we know to be positive as long as condition (10) is satisfied and $\bar{\alpha}_{t+1} \in$ $[0.5,1]$. Thus, under regime $J$, with $J=N, P, R$, inequality can be written as:

$$
I_{t+1}^{J}=\left(y_{t+1}^{R}-y_{t+1}^{P}\right)=\left(\bar{H}_{t}^{J}\right)^{\delta}\left(e_{t}^{J}\right)^{\xi}\left(2 \bar{\alpha}_{t+1}-1\right)\left(A^{H}-A^{L}\right)
$$

\footnotetext{
${ }^{22}$ This is not surprising, given that we have adopted their Cobb-Douglas model of capital formation. Notice, however, that Glomm and Ravikumar (1992) compare economic growth in a public versus a private education system, while we compare within a public education system the consequences on growth of the different political conditions.

${ }^{23}$ In particular, this is the case in which the economy gets unbounded growth under regime $J$; otherwise the economy may also end up in the trivial steady-state in which income is zero. (This trivial steady-state applies to all cases $a$ ), b) and $c$ ) under all regimes $J=N, P, R$; see Fig. 3).
} 
FiguRE 3: Income dynamics under time-invariant political regimes

a) Decreasing returns

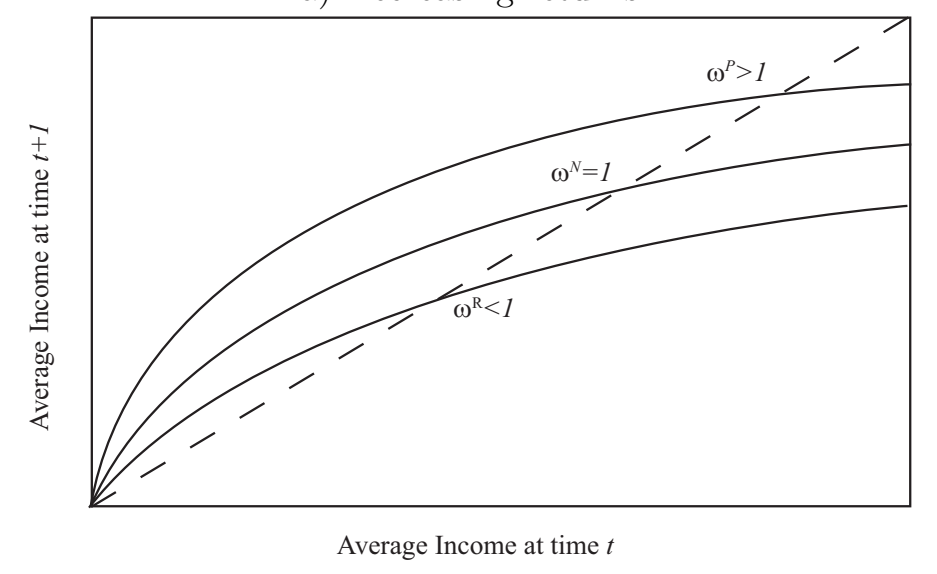

b) Constant returns

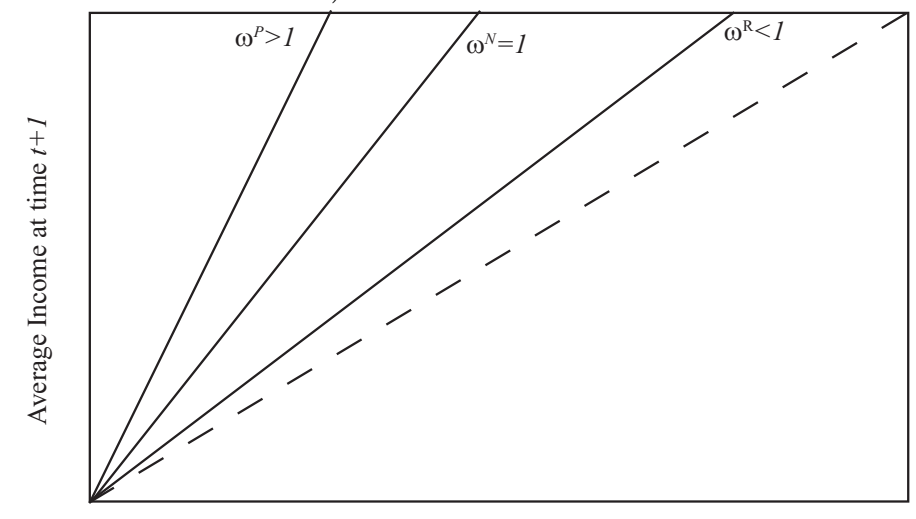

Average Income at time $t$

c) Increasing returns

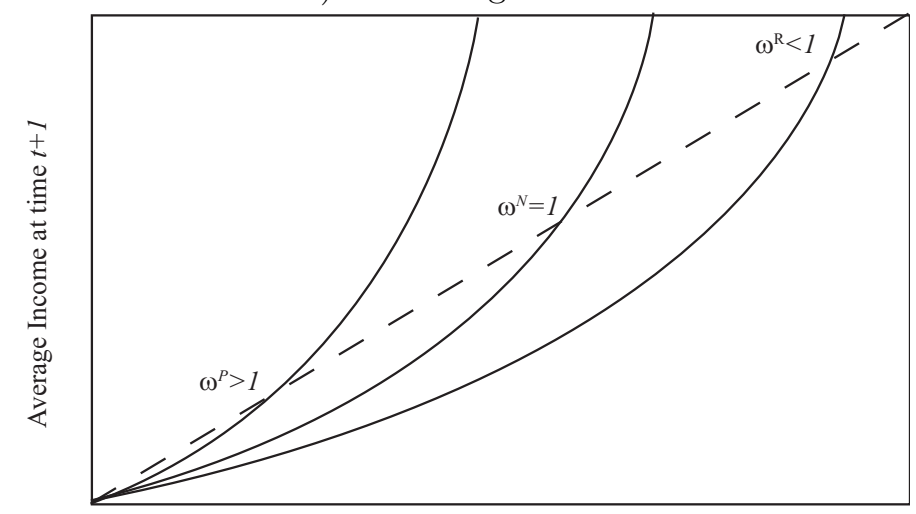

Average Income at time $t$ 
For all $t$, the greater is the mismatch, the lower is inequality ${ }^{24}$. Intuitively, more mismatch implies a lower income for the rich (reduced by the presence of low talented people in their class) and a higher income for the poor (increased by the presence of high talented people in their class) ${ }^{25}$. Therefore, the evolution of inequality depends on the dynamic of the mismatch under the three political regimes.

Proposition 3 . Given time-invariant $\omega^{J}$ under political regimes $J=$ $N, P, R$, the fractions of people with the "right" talent in each class converge to values of steady state given by $\bar{\alpha}_{v}^{N}, \bar{\alpha}_{v}^{P}, \bar{\alpha}_{v}^{R}$, with $1 \geq \bar{\alpha}_{v}^{P}>\bar{\alpha}_{v}^{N}>\bar{\alpha}_{v}^{R} \geq$ 0.5 . Further, given some initial condition $\bar{\alpha}_{0} \in[0.5,1]$ under all regimes, it is also $1 \geq \bar{\alpha}_{t+1}^{P}>\bar{\alpha}_{t+1}^{N}>\bar{\alpha}_{t+1}^{R} \geq 0.5$ for all $t=0,1,2, \ldots$.

Since the rich are those who mostly (only) benefit from the mismatch, when they have more political influence, the mismatch is comparatively higher.

Substituting now in equation (19) the values of $e_{t}^{J}=\left(1-\gamma^{J}\right) \tau^{J} \bar{y}_{t}^{J}$ found in Proposition 1 for the different regimes $J=N, P, R$, dating the same equation one period back, we can derive the following dynamic equation for the inequality:

$$
I_{t+1}^{J}=I_{t}^{J}\left(\frac{\bar{y}_{t}^{J}}{\bar{y}_{t-1}^{J}}\right)^{\xi+\delta}\left(\frac{2 \bar{\alpha}_{t+1}^{J}-1}{2 \bar{\alpha}_{t}^{J}-1}\right)
$$

Under all political regimes $J=N, P, R$, when $\bar{\alpha}_{t+1}^{J}$ are in steady-states $\bar{\alpha}_{v}^{J}$, inequality evolves with economic growth. In particular, inequality increases if the economy is growing; it stays constant if the economy is at the steady-state of average income $\bar{y}_{s}^{J}$; it decrease if the economic growth rate is negative. Before the $\bar{\alpha}_{t+1}^{J \prime} s$ have reached their respective steady-states $\bar{\alpha}_{v}^{J}$, growth and inequality may move in opposite directions depending on whether the initial condition $\bar{\alpha}_{0}$ is greater or lower than the steady states $\bar{\alpha}_{v}^{J}$ themselves 26 . Fig. 4 illustrates three examples, under the three regimes,

\footnotetext{
${ }^{24}$ In particular, $\frac{\partial I_{t+1}^{J}}{\partial \bar{\alpha}_{t+1}}=2\left(\bar{y}_{t}^{J}\right)^{\delta}\left(e_{t}^{J}\right)^{\xi}\left(A^{H}-A^{L}\right)>0$.

${ }^{25}$ Thus, in our model education and inequality are positively related (more education reduces the mismatch, thus increasing inequality). Notice that the relation between education and inequality is not uncontroversial. An opposite, negative relation is found by Glomm and Ravikumar (1992) and Hassler, Rodriguez Mora and Zeira (2006), due to the fact that public education increases the number of skilled workers and reduces the number of unskilled (see also Tamura 1991). However, Hassler, Rodriguez Mora and Zeira (2006) also argue that more public education requires higher taxes. Skilled parents pay higher taxes, but they may also benefit more from education than unskilled parents, because they use education better (on the different returns from education see also Connolly and Gottschalk 2006). Thus, they may prefer more public education than unskilled parents. In this case, more public education may even increase inequality.

${ }^{26}$ Notice the different subscripts $v$ and $s$, for the steady-steates of $\bar{\alpha}_{t+1}^{J}$ and $\bar{y}_{t+1}^{J}$. This is because the two variables will typically reach the steady-state at different times. (In
} 
of the relationships between growth and pre-tax inequality for the case of decreasing returns.

Notice also that the fact that $\bar{\alpha}_{t+1}^{J \prime} s$ converge under all regimes to their steady-states, does not imply that in the long-run the impact of $\bar{\alpha}_{t+1}^{J \prime} s$ is irrelevant for inequality. On the contrary, given that a higher $\bar{\alpha}_{t+1}^{J}$ directly increases inequality for generation $t+1$, which evolves according to equation (20), under all regimes $J=N, P, R$, a higher trajectory of $\bar{\alpha}_{t+1}^{J}$ implies a higher $\left(y_{t+1}^{R}-y_{t+1}^{P}\right)$ at all $t=0,1,2, \ldots$. Thus, we can unambiguously compare inequality under the different political regimes.

Proposition 4 Given initial condition $\bar{\alpha}_{0} \in[0.5,1]$ and time-invariant $\omega^{J}$ under the three regimes $J=N, P, R$, then $I_{t+1}^{P}>I_{t+1}^{N}>I_{t+1}^{R}$ at all $t=$ $0,1,2, \ldots$

When the poor are more politically influent, the economy is characterized by a higher pre-tax inequality than under a "neutral" political regime, which in turn shows higher inequality than the regime supported by the rich.

These results deserve some comments. Technically they arise because both mismatch and economic growth are positively correlated with inequality, with both growth and inequality being higher in the first political regime (poor), followed by the second (neutral) and then by the third (rich). That higher mismatch is associated with more pre-tax inequality is (as it has been noted) intuitive. The relationship between growth and inequality is, on the other hand, one of the most debated in the literature ${ }^{27}$. In this paper, the nature of this relationship is based on the idea that a higher public education on one side increases growth by increasing the level of human capital, while on the other side it better shapes differences in human capitals due to talent, thus increasing pre-tax inequality. For the reason related to the mismatch, the political regime supported by the poor is the most inclined to public education, which induces more growth and more pre-tax inequality. At the same time, together with the "neutral" regime, the regime of the "poor" is also the most favorable of redistribution; so under the regimes

addition, while the steady-state of $\bar{\alpha}_{t+1}^{J}$ will always be reached and under all regimes see Proposition 3 - , the steady-state of the average income $\bar{y}_{t+1}^{J}$ 's may well fail to exist or to be reached under different conditions - see Section 4.1).

${ }^{27}$ In particular, in the ninenties various theories of endogenous growth, stimulated by the renewed interest in the Kuznets' curve, have theorized a negative relationship between inequality and growth. As however recently put by Forbes (2000), "a careful reading of this literaure indicates that such negative relationship is far less definitive than generally believed" (p. 869). In addition, while on the empirical side "the Kuznets curve — whereby inequality first increases and then decreases during the process of economic development - emerges as a clear empirical regularity... this relation does not explain the bulk of variations in inequality across countries or over time" (Barro 2000, p. 29). See also Perotti (1996) for a classical reference on the political economy literature of growth and inequality. 
Figure 4: Interaction between inequality and growth (example of decreasing returns)

a) $\omega^{N}=1$

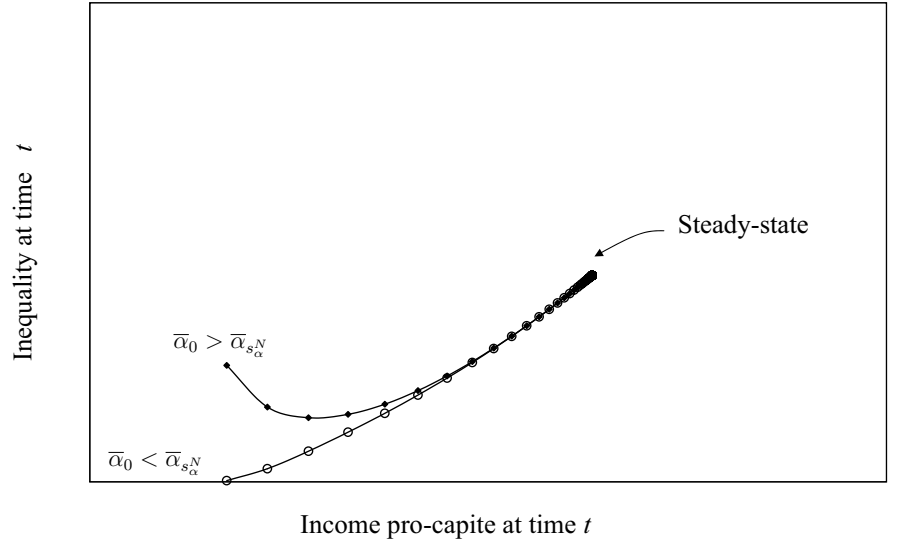

b) $\omega^{P}>1$

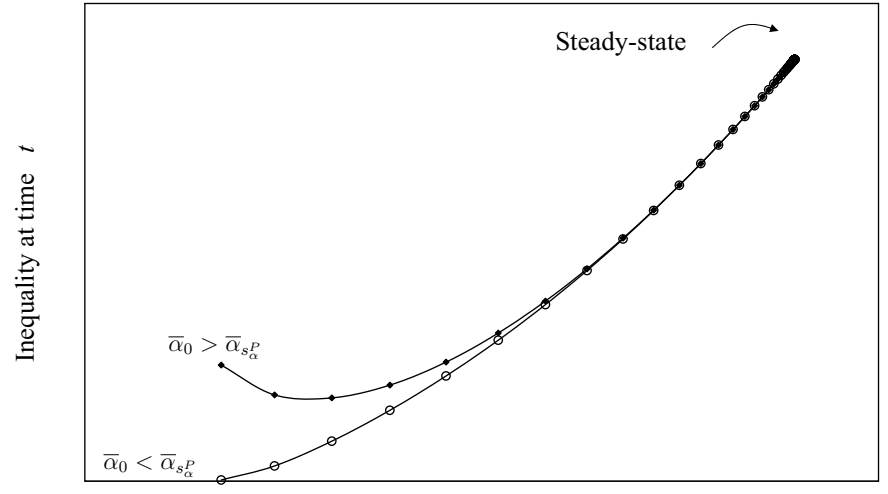

Income pro-capite at time $t$

c) $\omega^{R}<1$

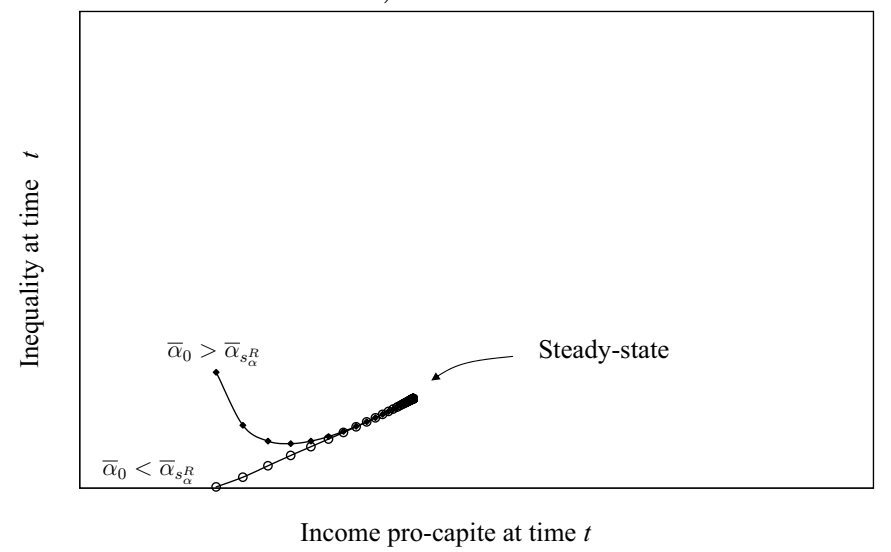


run by the poor, there is both maximum pre-tax inequality and minimum post-tax inequality ${ }^{28}$.

\subsection{Social mobility}

In our two social classes economy, social mobility is simply given by the probability $\left(1-\widetilde{p}_{t+1}\right)$ of class transition.

Proposition 5 . Under all regimes $j=N, P, R$, social mobility is given by:

$$
\left(1-\widetilde{p}_{t+1}^{J}\right)=1-c+d\left(1-\gamma_{t}^{J}\right) \tau_{t}^{J}
$$

For a time-invariant $\omega^{J}$ under each regime, the corresponding $\widetilde{p}_{t+1}^{J}$ is timeinvariant with $\widetilde{p}_{t+1}^{R}>\widetilde{p}_{t+1}^{N}>\widetilde{p}_{t+1}^{P}$.

As expected, social mobility is the highest when the poor are more politically influent; it reaches an intermediate value when rich and poor have the same political influence; and it is lowest when the rich are more politically influent. Social mobility is in fact good for the poor (upward mobility), while it is bad for the rich (downward mobility).

\section{The cost of the mismatch}

An implication of the results of the previous section is that a society with less mismatch is associated with more education, which induces more human capital and growth. The mismatch of talents, however, may also imply an efficient cost in production, which directly reduces growth. Though clearly expressed by Plato (see in particular the quotation at the top of the paper), this effect has not been enough emphasized by the economic literature 29 .

\footnotetext{
${ }^{28}$ A similar result is obtained by Saint-Paul and Verdier (1993) in a median voter model where people vote only on public education as redistributive program.

${ }^{29}$ Only recently some papers have addressed similar issues, but in rather different approaches. For example, Murphy, Shleifer and Vishny (1991) study the implications for growth of the allocation of talent when individuals may choose between occupations (entrepreneurs or rent-seeking). Similarly, Galor and Tsiddon (1997) and Hassler and Rodriguez Mora (2000) show that when individuals have more returns from becoming entrepreneurs (due, for instance, to technological changes), intelligence is more important than social backgrounds for the allocation of individuals, and thus a more efficient allocation emerges, which is associated with a higher growth. In a similar line, Gennaioli and Caselli (2005) also show that failures of meritocracy, such as dynastic management, may reduce growth. Maoz and Moav (1999) focus on liquidity constraints. They demonstrate that in societies in which education is privately acquired, liquidity constraints may prevent high talented people of poor families to access higher education, with a loss of efficiency. In most of the above studies, however, the misallocation of resources is before investing in human capitals, while in our model it occurs also after the financing of public education. Its costs may therefore be relatively higher, as we explain in this section.
} 
We illustrate this point in a simple model. We assume that individuals' human capitals, rather than determining directly their productivity, are perfect complement in the production process. Though this hypothesis would seem specific, it clarifies a general point. Suppose that there is a single industry employing all workers and producing all GDP using a basic Leontieff technology, which can be reproduced as many times one wishes. That is, pairing any two workers $l$ and $f$ of generation $t+1$, the technology produces an homogenous output $q_{t+1, l f}$ according to the production function:

$$
q_{t+1, l f}=2 \operatorname{Min}\left\{h_{t+1, l} ; h_{t+1, f}\right\}
$$

where $h_{t+1, l}$ and $h_{t+1, f}$ are the human capitals of the two workers. Clearly, since there are only two qualities of human capital in the economy, namely $h_{t+1}^{L}=e_{t}^{\xi} H_{t}^{\delta} A^{L}$ and $h_{t+1}^{H}=e_{t}^{\xi} H_{t}^{\delta} A^{H}$, it follows that any pair of workers can provide only two levels of output: a low output $q_{t+1}^{L}=2 e_{t}^{\xi} H_{t}^{\delta} A^{L}$, when either both or even only one of the two workers has low talent; or a high output $q_{t+1}^{H}=2 e_{t}^{\xi} H_{t}^{\delta} A^{H}$, when both workers have high talent.

Thus, if society wishes to obtain the maximum overall output from all workers, it would be necessary to pair all individuals with low talent on one side, and all individuals with high talent on the other side. If society could recognize people's talent without any mistake, social classes could be formed accordingly, with incomes of people with low talent (namely the "poor") given by $y_{t+1}^{P}=\frac{q_{t+1}^{L}}{2}=e_{t}^{\xi} H_{t}^{\delta} A^{L}$ and income of people with high talent (namely the "rich") given by $y_{t+1}^{R}=\frac{q_{t+1}^{H}}{2}=e_{t}^{\xi} H_{t}^{\delta} A^{H}$. These would also be the incomes of the poor and of the rich, respectively, in a society in which people 's productivity is given by their human capital and all individuals are put in the correct social class.

Suppose, however, that some mismatch of the form described in Section 2.4 occurs when forming the social classes ${ }^{30}$. Thus, a fraction $\bar{\alpha}_{t+1}$ of workers with $h_{t+1}^{L}$ and a fraction $\left(1-\bar{\alpha}_{t+1}\right)$ of workers with $h_{t+1}^{H}$ enter the group of people "recognized" with low talent, while symmetric proportions enter the group of people "recognized" with high talent. By applying the HardyWeinberg Principle of the allele frequencies we then have that 31 : i) among

\footnotetext{
${ }^{30}$ To be more consistent with the idea of the mismatch illustrated in Section 2.4, one should in fact add a random effect to the Leontieff production technology (22) (similar indeed to that assumed in equation (4) of footnote 7), justifying the hypothesis of imperfect information, namely that individuals' talents cannot be observed either directly, through inspection of human capitals, or even indirectly through the individuals' productivity.

${ }^{31}$ In its simplest form used here, the Hardy-Weinberg Principle of population genetics implies that randomly pairing all workers from a set containing a proportion $q$ of workers with human capitals $h_{t+1}^{L}$ and a proportion $(1-q)$ of workers with human capital $h_{t+1}^{H}$, the genotypic frequency of $\left(h_{t+1}^{L}, h_{t+1}^{L}\right)$ is $q^{2}$, that of $\left(h_{t+1}^{L}, h_{t+1}^{H}\right)$ is $2(1-q) q$, and that of $\left(h_{t+1}^{H}, h_{t+1}^{H}\right)$ is $(1-q)^{2}$. By definining $q$ and $(1-q)$ in terms of $\bar{\alpha}_{t+1}$ according to the prorportions specified for the two social classes (and applying the Leontieff production function to the various pairs), one obtains the results given in text.
} 
the people recognized with low talent, namely the "poor", there are $(1-(1-$ $\left.\left.\bar{\alpha}_{t+1}\right)^{2}\right)$ pairs producing $q_{t+1}^{L}=2 e_{t}^{\xi} H_{t}^{\delta} A^{L}$ and $\left(1-\bar{\alpha}_{t+1}\right)^{2}$ pairs producing $q_{t+1}^{H}=2 e_{t}^{\xi} H_{t}^{\delta} A^{H}$; while ii) among the people recognized with high talent, namely the "rich", there are $\bar{\alpha}_{t+1}^{2}$ pairs producing $q_{t+1}^{H}=2 e_{t}^{\xi} H_{t}^{\delta} A^{H}$ and $\left(1-\alpha_{t+1}^{2}\right)$ pairs producing $q_{t+1}^{L}=2 e_{t}^{\xi} H_{t}^{\delta} A^{L}$.

Individual incomes for people of each class, which we take to correspond to the average levels of output produced by all people of the same class, are then given for the "poor" and the "rich" by, respectively:

$$
\begin{aligned}
y_{t+1}^{P} & =\left(1-\left(1-\bar{\alpha}_{t+1}\right)^{2}\right) e_{t}^{\xi} H_{t}^{\delta} A^{L}+\left(1-\bar{\alpha}_{t+1}\right)^{2} e_{t}^{\xi} H_{t}^{\delta} A^{H} \\
y_{t+1}^{R} & =\left(1-\bar{\alpha}_{t+1}^{2}\right) e_{t}^{\xi} H_{t}^{\delta} A^{L}+\bar{\alpha}_{t+1}^{2} e_{t}^{\xi} H_{t}^{\delta} A^{H}
\end{aligned}
$$

The overall average output is equal to:

$$
\bar{y}_{t+1}=0.5 e_{t}^{\xi} H_{t}^{\delta}\left[\left(1+2 \bar{\alpha}_{t+1}-2 \bar{\alpha}_{t+1}^{2}\right) A^{L}+\left(1-2 \bar{\alpha}_{t+1}+2 \bar{\alpha}_{t+1}^{2}\right) A^{H}\right]
$$

Thus, in this new setting, per-capita income depends on the extent of the mismatch $\bar{\alpha}_{t+1}$. In fact, since $\frac{\partial \bar{y}_{t+1}}{\partial \bar{\alpha}_{t+1}}>0$ (when $\left.\bar{\alpha}_{t+1} \in[0.5,1]\right)$, the greater is the mismatch, the lower is average output.

The mismatch generates here a loss of output because, when workers with high talent are paired with workers with low talent, the higher productivity of the former is constrained by the lower productivity of the latter, due to the Leontieff technology. The Leontieff technology however is only an example for the general problem caused by the mismatch when the productivity of an individual does not depend only on the individual's human capital, but also on the use that the society is able to make of such human capital.

To this respect, the Leontieff example provides also a simple setting to analyze the cost of the mismatch in terms of the waste of human capital it generates. To see this, first of all notice that the new setting has not affected the way in which human capitals in society are formed, so that average human capital continues to be determined according to formula $\bar{H}_{t+1}=0.5 e_{t}^{\xi} H_{t}^{\delta}\left[A^{L}+A^{H}\right]$. Substituting in equation (25), we obtain the following relationship between current average income and current human capital (the index $J$ indicates the political regime):

$$
\bar{y}_{t+1}^{J}=\bar{H}_{t+1}^{J} \cdot F\left(\bar{\alpha}_{t+1}^{J}\right)
$$

where $F\left(\bar{\alpha}_{t+1}^{J}\right)=\frac{\left[\left(1+2 \bar{\alpha}_{t+1}-2 \bar{\alpha}_{t+1}^{2}\right) A^{L}+\left(1-2 \bar{\alpha}_{t+1}+2 \bar{\alpha}_{t+1}^{2}\right) A^{H}\right]}{\left[A^{L}+A^{H}\right]}$, so that $\bar{y}_{t+1}^{J}=\bar{H}_{t+1}^{J}$ if and only if $\bar{\alpha}_{t+1}^{J}=1$; whereas (since $\frac{\partial \bar{y}_{t+1}}{\partial \bar{\alpha}_{t+1}}>0$, for $\bar{\alpha}_{t+1}^{J} \in[0.5,1]$ ) the lower is $\bar{\alpha}_{t+1}^{J}$, the lower is $\bar{y}_{t+1}^{J}$ relative to $\bar{H}_{t+1}^{J}$.

Moreover, we can compare the dynamics of the average human capital and the average income to see how the waste of human capital evolves 
in a society with costly mismatch. First, after simple manipulations, the dynamics equation of the average income can be written as:

$$
\bar{y}_{t+1}^{J}=B^{J}\left(\bar{y}_{t}^{J}\right)^{\xi+\delta} \cdot \frac{F\left(\bar{\alpha}_{t+1}^{J}\right)}{F\left(\bar{\alpha}_{t}^{J}\right)^{\delta}}
$$

where $B^{J \prime} s$ are under all regimes the same as in economies without costly mismatch (see Proposition 2) ${ }^{32}$. Thus, when $\bar{\alpha}_{t+1}^{J}$ have reached their values of steady-state $\bar{\alpha}_{v}^{J}$, the conditions under the three political regimes for the economies to be growing, for existence of steady-state incomes $\bar{y}_{s}^{J}$ 's and for characterizing the relationships amongst steady-states and long-run growth rates are here the same as in the economy without costly mismatch. Namely, they only depend on the sum $\delta+\xi^{33}$.

Moreover, since we also know that in an economy without costly mismatch it is $\bar{y}_{t}^{J}=\bar{H}_{t}^{J}$ at all $t$, the distance between average income and average human capital in an economy with costly mismatch increases, stays constant or decreases, depending on whether the economy is growing, is in steady-state, or it is contracting ${ }^{34}$. Fig. 5 illustrates the point with three examples: a) decreasing returns (in the formation of human capital) with the economy growing to the steady-state; b) decreasing returns with the economy contracting to the steady-state; and c) constant returns with the waste of human capital increasing over time.

Finally, it is worthwhile noticing that, although from a qualitative perspective the above arguments hold equally true in all political regimes, they nevertheless apply more strongly depending on the extent of the mismatch carried by $\bar{\alpha}_{t+1}^{J}$ under the three regimes. Thus, since we already know from Proposition 3 that $\bar{\alpha}_{t+1}^{P}>\bar{\alpha}_{t+1}^{N}>\bar{\alpha}_{t+1}^{R}$ at all $t$, it follows that the arguments of the costly mismatch reinforce the conclusions of the previous section, that regimes supported by the poor are better for growth than neutral regimes, which in turn are better than regimes favored by the rich 35 .

${ }^{32}$ In particular, from equation (25), mean income can be rewritten as:

$$
\begin{aligned}
\bar{y}_{t+1} & =0.5 e_{t}^{\xi} H_{t}^{\delta}\left[F\left(\bar{\alpha}_{t+1}^{J}\right)\left(A^{L}+A^{H}\right)\right] \\
& =B^{J}\left(\bar{y}_{t}^{J}\right)^{\xi}\left(H_{t}^{J}\right)^{\delta} F\left(\bar{\alpha}_{t+1}^{J}\right)
\end{aligned}
$$

where $B^{J}=0.5\left(A^{L}+A^{H}\right)\left[\left(1-\gamma^{J}\right) \tau^{J}\right]^{\xi}$ as in Proposition 2, Substituting now equation $\bar{H}_{t}^{J}=\frac{\bar{y}_{t}^{J}}{F\left(\bar{\alpha}_{t}^{J}\right)}$ dated one period backwards one obtains equation (27).

${ }^{33}$ This clealry depends on the Leontieff production function with constant returns. But again the point is more general and it can be easily accomodated for production functions with increasing or decreasing returns.

${ }^{34}$ This in particular applies when $\bar{\alpha}_{t+1}^{J}$ are in steady-state $\bar{\alpha}_{v}^{J}$. When $\bar{\alpha}_{t+1}^{J \prime}$ 's are not yet in steady-states, growth in the economies with and without costly mismatch may for sometimes be uncoordinated (that is, one economy may be growing while the other is contracting, and viceversa) depending on whether the initial condition $\bar{\alpha}_{0}$ is greater or lower than the steady states $\bar{\alpha}_{v}^{J}$ of the different political regimes (see also Fig. 5 ).

${ }^{35} \mathrm{~A}$ similar discussion holds regarding inequality. In particular, inequality is now given 
Figure 5: Economic dynamics when mismatch is costly

a) Decreasing returns: growth to steady-state

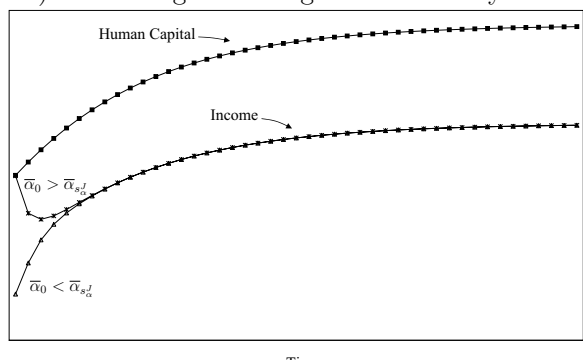

b) Decreasing returns: contraction to steady-state

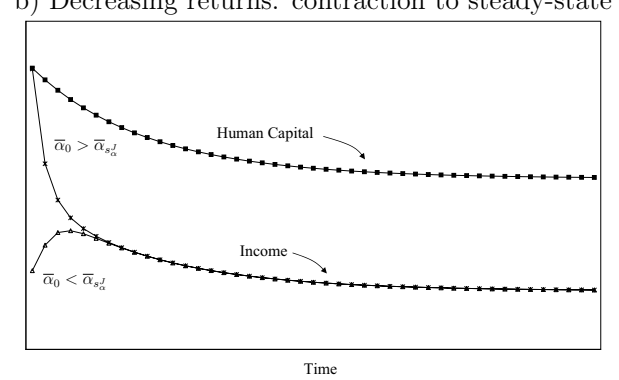

c) Constant returns

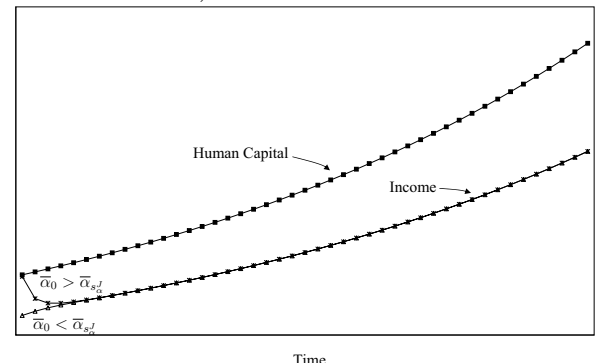

\section{Conclusions}

We have presented a political economy model in which the two social classes of rich and poor compete over redistribution and public education policies. Our model emphasizes crucial effects of public education. Firstly, as it is standard in the economic literature, education increases economic growth, which is positive for the all society. Secondly, and this is the more original contribution of the paper, education affects the mismatch between talents and social classes. In particular, education reduces the probability that individuals with low talent but coming from rich families are placed in jobs which should be reserved to people with high talent (and viceversa). Thus, education promotes equality of opportunity. The political behaviours of both social classes are then driven by strategic incentives, mainly for the poor to increase public education at the expense of pure redistribution in order to improve upward mobility, and for the rich to reduce public education to

by:

$$
I_{t+1}^{J}=I_{t}^{J}\left(\frac{\bar{y}_{t}^{J}}{\bar{y}_{t-1}^{J}}\right)^{(\xi+\delta)}\left(\frac{\bar{\alpha}_{t-1}^{J}\left(A^{H}-A^{L}\right)+2 A^{L}}{\bar{\alpha}_{t}^{J}\left(A^{H}-A^{L}\right)+2 A^{L}}\right)^{\delta}\left(\frac{\bar{\alpha}_{t+1}^{J}}{\bar{\alpha}_{t}^{J}}\right)
$$

When $\bar{\alpha}_{t}^{J}$ is in steady-state, since all factors containing $\bar{\alpha}_{t}^{J}$ are equal to 1 , inequality evolves with economic growth as in the economy without costly mismatch, but with the different growth rates resulting from the effect of the mismatch. (When $\bar{\alpha}_{t}^{J \prime}$ 's are not yet in steady-states, the dynamics may be a bit more complex due the interaction between the two factors containing $\bar{\alpha}_{t}^{J}$ at different $t$ ). 
avoid downward mobility. As a consequence, the equilibrium depends on which social class is more politically influent.

As any theoretical model, our model represents a simplification of the reality. First of all, in our setting there is only public education. This was to emphasize the impact of public education on mobility independently from considerations related to imperfections of capital markets as in most of the previous literature (see, e.g. Checchi 2006, and references therein). When private education is possible, our model can however be extended. In particular, with private education any dollar spent by poor parents and by rich parents for the education of their kids would affect differently the mismatch of talent and social mobility: namely, the dollars spent by poor fathers would increase mobility and reduce the talents mismatch, while the opposite would be true for the dollars spent by rich fathers. Other interesting implications of the social conflict over mobility may then emerge. For example, when private education is possible, redistribution could represent for the poor a way alternative to capital markets to buy private education for their kids. As a consequence, for low level of redistribution, the rich may prefer a system with only private education, while for high level of redistribution they may prefer one with only public education in order to stop the poor buying privately even more education to increase exchange mobility.

Another simplification of the present model is that all individuals of the same class have identical beliefs on their kids' prospect of mobility. Introducing different beliefs would not change the flavor of our results, though delivering further interesting possibilities 36 . If, for instance, we allow a fraction of poor individuals to believe that their kids have high talent and another fraction that theirs have low talent, the former fraction will prefer more education than the second one. As a consequence, even in a pure system of public education, a majoritarian coalition of rich and poor individuals believing in the low talent of their kids may emerge, which could endorse a political equilibrium with more redistribution and less education and taxation than the one that we obtain in our model when the poor are more politically influent ${ }^{37}$. However, even in this case, the latent conflict between the two social classes on mobility would not disappear, with the final outcome depending on the fractions of poor agents having different beliefs of upward mobility.

Other more technical extensions could also be considered, like the effect of distortionary taxation, or of endogenous labor supply. But, ultimately, as in any theoretical abstraction, the strength of the present model depends on its ability to capture stylized facts of the real world. To this respect

\footnotetext{
${ }^{36}$ See Piketty (1995) and Bénabou and Ok (2001), as seminal theoretical papers on the various factors which may influence people beliefs of mobility; see Fong (2001) and Alesina and La Ferrara (2005), for empirical studies.

${ }^{37} \mathrm{Such}$ extension could in particular be conducted along the theoretical model of Levy (2005), where individuals differ within the class of the poor according to their age.
} 
we emphasize that the mismatch between talents and allocation of people in social classes is a quite clear implication of any society which lacks of equality of opportunity. Any realistic economic model of education and social mobility should include a mismatch mechanism. However, despite a very large literature reasoning informally on the topic, we are not aware of previous contributions detailing the precise mechanism through which the mismatch can occur (as in particular in Fig. 1 and Sections 2.4). An advantage of our specification is also that mismatch is modelled in a quite general setting, which could be generalized to include, further to education, other factors or public policies (like health, security, liberalization policies) possibly affecting the talents mismatch and mobility.

Our model provides material for new empirical investigations. In particular, there are not many studies comparing pure redistributive programs versus public education across countries 38 . The present paper offers a framework to study the effect of political influence. Specifically, is there any evidence that right-oriented governments (more likely to be supported by the rich) become increasingly more hostile to public education spending, while softer on pure redistributive policies, the greater is the degree of openness in society (a lower value of parameter $c$ in the present paper) and the higher the effect of education on mobility (a higher parameter $d$ )? Also, is it true that more politically "neutral" governments spend more on redistribution and less on education than more left-oriented governments, even when they impose similar overall levels of taxation?

Of specific empirical interest could also be the relationships between mobility, talents mismatch and economic growth, in particular the results of Section 5, on the growing waste of social capital generated by the mismatch when people with low talent are allocated in jobs of higher potential productivity. This may for example be important to explain the recent poorer performance of some well-developed countries relative to others, which appear indeed characterized by high levels of redistribution and low levels of mobility (like notably Italy; Checchi, Ichino and Rustichini 1999).

More generally, various recent studies have emphasized a trade-off between mobility and redistribution, noting that the political support for redistribution tends to be lower in societies where social mobility is higher (see e.g. Bénabou and Ok 2001, and Alesina and La Ferrara 2005). These studies, however, have generally treated mobility as exogenous to the political process. It may be interesting to verify to what extent the idea of a social conflict over mobility can explain more general differences (regarding public education, but possibly also other public policies) of welfare models across

\footnotetext{
${ }^{38}$ Among the few studies, Lindert (1996) compares welfare transfers programs and public education expenditures across OECD countries over the period 1960-1981. He focuses especially on the effect of the size of cohorts of different age. It is therefore more relevant to study the intergenerational conflict on the demand of public education (Levy 2005), rather than the political conflict.
} 
countries and their implications for growth and mobility (as for example recently reviewed in Solon 2002).

\section{References}

[1] Alesina, A. and E. La Ferrara (2005). "Preferences for Redistribution in the Land of Opportunities", Journal of Public Economics 89, pp. 897-931.

[2] Atkinson (1981) "The Measurement of Economic Mobility", in A.B. Atkinson, Essays in Honor of Jan Penn (editor), reprinted in Social Justice and Public Policy, Chapter 3, (1983). London: Wheatsheaf Books Ltd..

[3] Barro, R.J. (2000). "Inequality and Growth in a Panel of Countries", Journal of Economic Growth 5, pp. 5-32.

[4] Becker, G.S. and N. Tomes (1979). "An Equilibrium Theory of the Distribution of Income and Intergenerational Mobility", Journal of Political Economy 87, pp. 1153-1189.

[5] Becker, G.S. and N. Tomes (1986). "Human Capital and the Rise and Fall of Families", Journal of Labour Economics 4, pp. s1-39.

[6] Bénabou, R. (1996). "Heterogeneity, Stratification, and Growth: Macroeconomic Implications of Community Structure and School Finance", American Economic Review 86, pp. 584-609.

[7] Bénabou, R. (2000). "Unequal Societies: Income Distribution and the Social Contract", American Economic Review 90, pp. 96-129.

[8] Bénabou, R., and E. Ok (2001) "Social Mobility and the Demand for Redistribution", Quarterly Journal of Economics 116, pp. 447-487.

[9] Bowles, S. and H. Gintis (2002). "The Inheritance of Inequality", Journal of Economic Perspectives 16, pp. 3-30.

[10] Bodway R. and M. Keen (2000). "Redistribution", in A.B. Atkinson and F. Bourguignon (eds.), Handbook of Income Distribution, vol. 1, pp. 677-789. Amsterdam: North-Holland.

[11] Breen, R. and J.O. Jonsson (2005). "Inequality of Opportunity in Comparative Perspective: Recent Research on Educational Attainment and Social Mobility", Annual Review of Sociology 31, pp. 223-243.

[12] Caselli, F. and Gennaioli, N. (2005) "Dynastic Management", mimeo London School of Economics. 
[13] Checchi, D., A. Ichino and A. Rustichini (1999). "More Equal but Less Mobile? Education Financing and Intergenerational Mobility in taly and in the US", Journal of Public Economics 74, pp. 351-393.

[14] Checchi, D. (2006). The Economics of Education: Human Capital, Family Background and Inequality. Cambridge: Cambridge University Press.

[15] Connolly, H. and Gottschalk, P. (2006). "Differences in Wage Growth by Education Level: Do Less-Educated Workers Gain Less from Work Experience?" IZA WP No 2331.

[16] Coughlin, P.C. and S. Nitzan (1981a). "Directional and Local Electoral Equilibria with Probabilistic Voting", Journal of Economic Theory 34, pp. 1-12.

[17] Coughlin, P.C. and S. Nitzan (1982a). "Electoral Outcomes with Probabilistic Voting and Nash Social Welfare Maxima", Journal of Public Economics 15, pp. 113-121.

[18] Cremer, H. and Pestieau, P. (2004) "Intergenerational Transfer of Human Capital and Optimal Education Policy", mimeo University of Toulouse and University of Liege.

[19] Davies, J.B., J. Zhang and J. Zeng (2005). "Intergenerational Mobility under Private versus Public Education", Scandinavian Journal of Economics 107, pp. 399-417.

[20] Fernández, R. and R. Rogerson (1995). "On the Political Economy of Education Subsidies", Review of Economc Studies 62, pp. 249-262.

[21] Fernández, R. and R. Rogerson (1998). "Public Education and Income Distribution: a Dynamic Quantitative Evaluation of Education-Finance Reform", American Economic Review 88, pp. 813-833.

[22] Fields, G.S. and E. Ok (1999). "The Measurement of Income Mobility: an Introduction to the Literature", in J. Silber (ed.), Handbook of Inequality Measurement. Dordrecht: Kluwer Academic Publishers.

[23] Fong, C. (2001). "Social Preferences, Self-Interest, and the Demand for Redistribution", Journal of Public Economics 82, pp. 225-246.

[24] Forbes, K.J. (2000). "A Reassessment of the Relationship between Inequality and Growth", American Economic Review 90, pp. 869-887.

[25] Galor, O. and D. Tsiddon (1997). "Technological Progress, Mobility, and Growth", American Economic Review 60, pp. 35-52. 
[26] Galor, O. and J. Zeira (1993). "Income Distribution and Macroeconomics", Review of Economic Studies 60, pp. 35-52.

[27] Glomm, G. and B. Ravikumar (1992). "Public versus Private Investment in Human Capital: Endogenous Growth and Income Inequality", Journal of Political Economy 100, pp. 818-834.

[28] Glomm, G. and B. Ravikumar (1998). "Opting Out of Publicly Provided Services: a Majority Voting Result", Social Choice and Welfare 15, pp. 187-193.

[29] Gradstein, M. and M. Kaganovich (2004). "Aging Population and Education Finance", Journal of Public Economics 88, pp. 2469-2485.

[30] Harms, P. and S. Zink (2003). "Limits to Redistribution in Democracy: a Survey", European Journal of Political Economy 19, pp. 651-668.

[31] Hassler, J. and Rodriguez Mora, J.V. (2000) "Intelligence, Social Mobility and Growth", The American Economic Review 90, pp. 888-908.

[32] Hassler, J., Rodriguez Mora, J.V. and Zeira, J. (2006) "Inequality and Mobility", mimeo Stockolm University, Universitat Pompeu Fabra an Hebrew University of Jerusalem.

[33] Levy, G. (2005). "The Politics of Public Provison of Education", Quarterly Journal of Economics 120, pp. 1507-1534.

[34] Lindbeck, A. Weibull, J.W. (1987). "Balanced-budget Redistribution as the Outcome of Political Competition", Public Choice 52, pp. 273-297.

[35] Lindert, P. (1996). "What Limits Social Spending", Explorations in Economic History 33, pp. 1-34.

[36] Loury, G. (1981). "Intergenerational Transfers and the Distribution of Earnings", Econometrica 49, pp. 843-867.

[37] Maoz, Y.O. and O. Moav (1999). "Intergenerational Mobility and the Process of Development", Economic Journal 109, pp. 677-697.

[38] Murphy, K., Shleifer, A. and Vishny, R. (1991) "The Allocation of Talent: Implications for Growth", Quarterly Journal of Economics 106, pp.503-530.

[39] Perotti, R. (1996). "Growth, Income Distribution and Democracy: What the Data Say", Journal of Economic Growth 1, pp. 149-187.

[40] Persson, T. and G. Tabellini (2000). Political Economics: Explaining Economic Policy. Cambridge, MA: Cambridge University Press. 
[41] Piketty, T. (1995). "Social Mobility and Redistributive Politics", Quarterly Journal of Economics 110, pp. 551-585.

[42] Plug, E. and W. Vijverberg (2003). "Schooling, Family Background, and Adoption: Is it Nature or Is it Nurture?", Journal of Political Economy 111, pp. 611-641.

[43] Poterba, J.M. (1998). "Demographic Change, Intergenerational Linkages, and Public Education", American Economc Review, Papers and Proceedings 88, pp. 315-320.

[44] Restuccia, D. and C. Urrutia (2004). "Intergenerational Persistence of Earnings: the Role of Early and College Education", American Economic Review 94, pp. 1354-1378.

[45] Roemer, J. (1998). Equality of Opportunity. Cambride, MA: Harvard University Press.

[46] Sacerdote, B. (2002). "The Nature and Nurture of Economic Outcomes", American Economic Review, Papers and Proceedings 92, pp. 344-348.

[47] Saint-Paul, G. and T. Verdier (1993). "Education, Democracy and Growth", Journal of Development Economics 42, pp. 399-408.

[48] Shorrocks, A.F. (1978). "Measurement of Mobility", Econometrica 46, pp. 1013-1024.

[49] Solon, G. (1999). "Intergenerational Mobility in the Labour Market", in O.C. Ashenfelter and D.Card (eds.), Handboook of Labour Economics, vol. 3A, pp. 1761-1800. Amsterdam: North-Holland.

[50] Solon, G. (2002). "Cross-Country Differencs in Intergenerational Earnings Mobility", Journal of Economic Perspectives 16, pp. 59-66.

[51] Tamura, R. (1991). "Income Convergence in an Endogenous Growth Model", Journal of Political Economy 99, pp. 522-540.

\section{Appendix}

\section{Proof of Proposition 1}

The first order conditions for the maximization problem are: 


$$
\begin{aligned}
\mathrm{FOC}_{\tau}: \quad 0= & \frac{\omega\left(-y_{t}^{P}+\gamma_{t} \bar{y}_{t}\right)}{\left(1-\tau_{t}\right) y_{t}^{P}+\gamma_{t} \tau_{t} \bar{y}_{t}}+\frac{\left(-y_{t}^{R}+\gamma_{t} \bar{y}_{t}\right)}{\left(1-\tau_{t}\right) y_{t}^{R}+\gamma_{t} \tau_{t} \bar{y}_{t}} \\
& +\frac{(\omega+1) \xi}{\tau}-d\left(1-\gamma_{t}\right)(1-\omega)\left(\ln A^{H}-\ln A^{L}\right) \\
\mathrm{FOC}_{\gamma}: 0= & \frac{\omega \tau_{t} y_{t}}{\left(1-\tau_{t}\right) y_{t}^{P}+\gamma_{t} \tau_{t} \bar{y}_{t}}+\frac{\tau_{t} \bar{y}_{t}}{\left(1-\tau_{t}\right) y_{t}^{R}+\gamma_{t} \tau_{t} \bar{y}_{t}} \\
& -\frac{(\omega+1) \xi}{1-\gamma_{t}}+d \tau_{t}(1-\omega)\left(\ln A^{H}-\ln A^{L}\right)
\end{aligned}
$$

All variables are indexed at time $t$. Thus, we henceforth suppress the index $t$. Notice that $\mathrm{SOC}_{\tau}<0$ and $\mathrm{SOC}_{\gamma}<0$, for all $\gamma$ and $\tau$. Notice also that the solution of the maximization problem can be of three types: i) $\tau=1$ and $\gamma \in(0,1)$, ii) $\gamma=0$ and $\tau \in(0,1)$, iii $\tau \in(0,1)$ and $\gamma \in(0,1)$.

- Case $\omega \geq 1$.

It is useful to define the following functions:

$$
\begin{gathered}
C(\tau, \gamma, \omega)=\frac{\omega\left(-y^{P}+\gamma \bar{y}\right)}{(1-\tau) y^{P}+\gamma \tau \bar{y}}+\frac{\left(-y^{R}+\gamma \bar{y}\right)}{(1-\tau) y^{R}+\gamma \tau \bar{y}} \\
\xi(\tau, \gamma, \omega)=\frac{\omega+1}{\tau} \xi-d(1-\gamma)(1-\omega)\left(\ln A^{H}-\ln A^{L}\right)
\end{gathered}
$$

Notice that:

$$
\begin{aligned}
& \frac{\partial C(\tau, \gamma, \omega)}{\partial \tau}=\frac{-\omega\left(-y^{P}+\gamma \bar{y}\right)^{2}}{\left[(1-\tau) y^{P}+\gamma \tau \bar{y}\right]^{2}}+\frac{-\left(-y^{R}+\gamma \bar{y}\right)^{2}}{\left[(1-\tau) y^{R}+\gamma \tau \bar{y}\right]^{2}}<0 \\
& \frac{\partial C(\tau, \gamma, \omega)}{\partial \gamma}=\frac{\omega y^{P} \bar{y}}{\left[(1-\tau) y^{P}+\gamma \tau \bar{y}\right]^{2}}+\frac{\omega y^{R} \bar{y}}{\left[(1-\tau) y^{R}+\gamma \tau \bar{y}\right]^{2}}>0
\end{aligned}
$$

and that $\xi(\tau, \gamma, w)>0$ ( since $\omega \geqslant 1$, and $A^{H}>A^{L}$ ).

We proceed in four steps. In step 1) we show that for $\gamma=1$ and $\omega=1$, $\tau$ solving for $C(\tau, 1,1)=0$ is $\tau=1$; in step 2) we prove that for any $\omega \geqslant 1$ and any $\gamma^{*}$ satisfying $F O C_{\gamma}=0$ (equation 29 ), then

$$
C\left(\tau, \gamma^{*}, \omega\right)+\xi\left(\tau, \gamma^{*}, \omega\right)>C(\tau, 1,1)
$$

In step 3) we show that given condition (30), if an equilibrium exists when $\omega \geqslant 1$, then it is given by the pair $\left(\tau=1, \gamma=\gamma^{*}\right)$; in step 4$)$, we show that such an equilibrium exists and is unique; in particular, we show that when $\tau$ is optimally chosen to be equal 1 , then there is a unique $\gamma^{*}$ internal to the interval $(0,1)$ both when $\omega=1$ and when $\omega>1$; and it is $\gamma^{*}=\frac{1}{1+\xi}$ when $\omega=1$, and $0<\gamma^{*}<\frac{1}{1+\xi}$ when $\omega>1$. 
Step 1. When $\gamma=1$ and $\omega=1$,

$$
\begin{aligned}
C(\tau, 1,1)= & \frac{\left(-y^{P}+\bar{y}\right)}{(1-\tau) y^{P}+\tau \bar{y}}+\frac{\left(-y^{R}+\bar{y}\right)}{(1-\tau) y^{R}+\tau \bar{y}} \\
& \frac{0.5\left(y^{R}+y^{P}\right)}{(1-\tau) y^{P}+\tau 0.5\left(y^{R}+y^{P}\right)}-\frac{0.5\left(y^{R}+y^{P}\right)}{(1-\tau) y^{R}+\tau 0.5\left(y^{R}+y^{P}\right)}
\end{aligned}
$$

Thus, it is $C(\tau, 1,1)=0$ if and only if $\tau=1$.

Step 2. To prove condition (30) notice that for $\gamma^{*}$ solving $F O C_{\gamma}$ (equation 29), it must be:

$$
\frac{\omega \bar{y}\left(1-\gamma^{*}\right)}{(1-\tau) y^{P}+\gamma^{*} \tau \bar{y}}+\frac{\bar{y}\left(1-\gamma^{*}\right)}{(1-\tau) \bar{y}+\gamma^{*} \tau \bar{y}}=\xi\left(\tau, \gamma^{*}, \omega\right)
$$

Also notice that $C\left(\tau, \gamma^{*}, \omega\right)+\xi\left(\tau, \gamma^{*}, \omega\right)$ is the right-hand side of $F O C \tau$ (equation 28) when $\gamma^{*}$ solves $F O C_{\gamma}$. Hence, substituting from equation (31), FOC $\tau$ can be written as:

$$
\begin{aligned}
C\left(\tau, \gamma^{*}, \omega\right)+\xi\left(\tau, \gamma^{*}, \omega\right)= & C\left(\tau, \gamma^{*}, \omega\right)+\frac{\omega \bar{y}\left(1-\gamma^{*}\right)}{(1-\tau) y^{P}+\gamma^{*} \tau \bar{y}}+\frac{\bar{y}\left(1-\gamma^{*}\right)}{(1-\tau) \bar{y}+\gamma^{*} \tau \bar{y}} \\
= & \frac{\omega\left(-y^{P}+\gamma^{*} \bar{y}\right)}{(1-\tau) y^{P}+\gamma^{*} \tau \bar{y}}+\frac{\left(-y^{R}+\gamma^{*} \bar{y}\right)}{(1-\tau) y^{R}+\gamma^{*} \tau \bar{y}} \\
& +\frac{\omega \bar{y}\left(1-\gamma^{*}\right)}{(1-\tau) y^{P}+\gamma^{*} \tau \bar{y}}+\frac{\bar{y}\left(1-\gamma^{*}\right)}{(1-\tau) \bar{y}+\gamma^{*} \tau \bar{y}} \\
= & \frac{\omega\left(-y^{P}+\bar{y}\right)}{(1-\tau) y^{P}+\gamma^{*} \tau \bar{y}}+\frac{\left(-y^{R}+\bar{y}\right)}{(1-\tau) y^{R}+\gamma^{*} \tau \bar{y}}
\end{aligned}
$$

With such substitution, condition (30) can then be written as:

$$
\frac{\omega 0.5\left(y^{R}+y^{P}\right)}{(1-\tau) y^{P}+\gamma^{*} \tau \bar{y}}-\frac{0.5\left(y^{R}+y^{P}\right)}{(1-\tau) y^{R}+\gamma^{*} \tau \bar{y}}>\frac{0.5\left(y^{R}+y^{P}\right)}{(1-\tau) y^{P}+\tau \bar{y}}-\frac{0.5\left(y^{R}+y^{P}\right)}{(1-\tau) y^{R}+\tau \bar{y}}
$$

which is always satisfied when $\omega \geqslant 1, \gamma^{*} \in(0,1)$, and $y^{P}<y^{R}$.

Step 3. Step 3 is straightforward. In particular, given: a) that $C(\tau, \gamma, \omega)$ is decreasing in $\tau$ and increasing in $\gamma, b$ ) that $\xi(\tau, \gamma, w)>0$ (when $\omega \geqslant 1$ ), c) that $\tau$ solving $C(\tau, 1,1)=0$ is $\tau=1, d)$ that condition $(30) C\left(\tau, \gamma^{*}, \omega\right)+$ $\xi\left(\tau, \gamma^{*}, \omega\right)>C(\tau, 1,1)$ holds, and $\left.e\right)$ that $C\left(\tau, \gamma^{*}, \omega\right)+\xi\left(\tau, \gamma^{*}, \omega\right)$ is the righthand side of $F O C_{\tau}$ when $\gamma^{*}$ solves for $F O C_{\gamma}=0$, then it follows that when the optimal $\gamma$ is internal, then the optimal tax rate $\tau^{*}=1$.

Step 4. With step 3 we have shown that if there is a $\gamma^{*} \in(0,1)$ solving for $F O C_{\gamma}=0$ when $\omega \geqslant 1$, then the corresponding optimal $\tau^{*}=1$. We now show that such a $\gamma^{*}$ exists and is unique in the interval $(0,1)$. In doing this we also show that a $\gamma=0$ with a $\tau$ solving $F O C_{\tau}=0$ in the interval $(0,1)$ doesn't exist. This implies that the unique political equilibrium when $\omega \geqslant 1$ is indeed of type $\left(\tau^{*}=1, \gamma^{*} \in(0,1)\right)$. Next we compute the equilibrium 
$\gamma^{*}$ when $\omega=1$, obtaining $\gamma^{*}=\frac{1}{1+\xi}$; and show that $\frac{1}{1+\xi}$ is larger than the equilibrium $\gamma^{*}$ for $\omega>1$.

To prove existence and uniqueness of $\gamma^{*}$ in the interval $(0,1)$, first of all notice that $\lim _{\gamma \rightarrow 1} F O C(\gamma)=-\infty$. Together with the assumption that $S O C_{\gamma}$ holds (hence $\frac{\partial F O C_{\gamma}}{\partial \gamma}<0$ ), it follows that for the existence and uniqueness of $\gamma^{*} \in(0,1)$, it is sufficient to show that $F O C_{\gamma}(\tau=1, \gamma=0)>0$. The latter is always true since:

$F O C_{\gamma}(\gamma=0): \frac{\omega \tau \bar{y}}{(1-\tau) y^{P}}+\frac{\tau \bar{y}}{(1-\tau) y^{R}}-(\omega+1) \xi+d \tau(1-\omega)\left(\ln A^{H}-\ln A^{L}\right)$

so that $\lim _{\tau \rightarrow 1} F O C_{\gamma}(\gamma=0)=+\infty$. More generally, we now prove that $F O C_{\gamma}(\gamma=0)>0$ also for any $\tau \in(0,1)$ chosen so as to satisfy $F O C_{\tau}=0$. Since $\frac{\partial F O C(\gamma)}{\partial \gamma}<0$ always, this excludes the possibility of an optimum when $\gamma=0$ and $\tau$ internal in the interval $(0,1)$. When $\gamma=0$ and $\tau$ internal, from equation (28) we have:

$$
F O C_{\tau}(\gamma=0): \frac{-\tau(\omega+1)}{(1-\tau)}=-(\omega+1) \xi+d \tau(1-\omega)\left(\ln A^{H}-\ln A^{L}\right)
$$

Substituting - $(\omega+1) \xi+d \tau(1-\omega)\left(\ln A^{H}-\ln A^{L}\right)$ in $F O C_{\gamma}$ and imposing $\gamma=0$, one obtains the $F O C_{\gamma}(\gamma=0)$ with $\tau$ chosen so as to satisfy $F O C_{\tau}=0$. We define such expression as $\left.F O C_{\gamma}\right|_{\gamma=0, \tau \text { internal }}$ as:

$$
\begin{aligned}
\left.F O C_{\gamma}\right|_{\gamma=0, \tau \text { internal }} & : \frac{\tau}{1-\tau}\left[\frac{\omega \bar{y}}{y^{P}}+\frac{\bar{y}}{y^{R}}-(\omega+1)\right]= \\
& =\frac{\tau}{1-\tau}\left[\frac{\omega 0.5\left(y^{P}+y^{R}\right) y^{R}+0.5\left(y^{P}+y^{R}\right) y^{R}}{y^{P} y^{R}}-(\omega+1)\right] \\
& =\frac{0.5 \tau}{1-\tau}\left[\frac{\omega y^{R}}{y^{P}}+\frac{y^{P}}{y^{R}}-(\omega+1)\right]
\end{aligned}
$$

The latter expression then gives:

$$
\begin{gathered}
\text { iff }\left._{\gamma}\right|_{\gamma=0, \tau} \text { internal } \frac{\geq}{<} 0 \\
{\left[\frac{\omega y^{R}}{y^{P}}+\frac{y^{P}}{y^{R}}-(\omega+1)\right]\left\{\begin{array}{c}
>0 \text { if either } \frac{y^{R}}{y^{P}}<1 \text { or } \frac{y^{R}}{y^{P}}>\frac{1}{\omega} \\
=0 \text { if either } \frac{y^{R}}{y^{P}}=1 \text { or } \frac{y^{R}}{y^{P}}=\frac{1}{\omega} \\
<0 \text { iff } 1<\frac{y^{R}}{y^{P}}<\frac{1}{\omega}
\end{array}\right.}
\end{gathered}
$$

The case $\frac{y^{R}}{y^{P}}>\frac{1}{\omega}$ applies to the present situation (since $y^{R}>y^{P}$ and $\omega \geq 1$ ) which then excludes the possibility of a solution with $\gamma=0$ and $\tau$ internal when $\omega \geq 1$. We now compute the equilibrium value of $\gamma$ when $\omega=1$ and $\tau^{*}=1$, and then show that it is greater than the equilibrium value of $\gamma$ when $\omega>1$. Define the function $G(\omega, \gamma)$ as:

$$
G(\omega, \gamma)=\frac{\omega+1}{\gamma}-\frac{(\omega+1) \xi}{1-\gamma}
$$


Notice now that for $\gamma=\frac{1}{1+\xi}$, then $G(\omega, \gamma)=0$ all $\omega$. Hence, since $G(\omega=$ $1, \gamma)=F O C_{\gamma}(\omega=1, \tau=1, \gamma)$, it follows that for $\omega=1$ the equilibrium is given by the pair $\left(\tau=1, \gamma=\frac{1}{1+\xi}\right)$. For $\omega>1$ and $\tau=1, F O C_{\gamma}(\omega>1, \tau=$ $1, \gamma)$ is:

$$
\operatorname{FOC}_{\gamma}(\omega>1, \tau=1, \gamma)=G(\omega, \gamma)+(1-\omega) S
$$

where $S=d\left(\ln A^{H}-\ln A^{L}\right)$. Since $\frac{\partial F O C_{\gamma}}{\partial \gamma}$ is always negative and $(1-\omega) S<$ 0 , it follows that $\gamma$ solving for $F O C_{\gamma}(\omega>1, \tau=1)=0$ is strictly lower than $\gamma=\frac{1}{1+\xi}\left(\right.$ which solves for $\left.F O C_{\gamma}(\omega=1, \tau=1)=0\right)$. The actual value of $\gamma$ $(<1)$ solving equation 34 is given by:

$$
\begin{aligned}
\gamma= & \frac{1}{-2 S(1-\omega)} \cdot[(\omega+1)(1+\xi)-S(1-\omega) \\
& \left.-\sqrt{((\omega+1)(1+\xi)-S(1-\omega))^{2}+4 S(1-\omega)(\omega+1)}\right]
\end{aligned}
$$

(Equation (35) has also been used to draw the graphs of $\tau \gamma$ and $\tau(1-\gamma)$ in Fig. 2 when $\omega>1$, since in this case $\tau=1$ ).

- Case $\omega<1$.

Firstly we show that there isn't a solution with $\tau=1$ when $\omega<1$. This follows by noting that when $\tau=1$, then a solution can only exist with $\gamma$ internal. This requires finding a $\widehat{\gamma}$ which solves $F O C_{\gamma}(\tau=1)$. Then, it is possible to show that for such a $\widehat{\gamma}$ (and $\omega<1$ ), it is always $F O C_{\tau}(\tau=$ $1, \gamma=\widehat{\gamma})<0$. Hence, since $\lim _{\tau \rightarrow 0} F O C_{\tau}=+\infty$ for any $\gamma \in(0,1)$ and since $S O C_{\tau}$ holds, it follows that a solution with $\widehat{\gamma}$ internal and $\tau=1$ cannot hold when $\omega<1$.

Hence, a solution when $\omega<1$ always requires $F O C_{\tau}$ satisfied with equality and $\tau$ internal. Reconsider then $F O C_{\gamma}$ and also recall the expressions in equation (33) giving the conditions for $\left.F O C_{\gamma}\right|_{\gamma=0, \tau \text { internal }} \geq 0$. Since $\frac{\partial F O C_{\gamma}}{\partial \gamma}<0$ and $\lim _{\gamma \rightarrow 1} F O C_{\gamma}=-\infty$, the inequalities in (33) point out the conditions when the optimal $\gamma$ for $\tau$ internal can be of two types: either i) $\gamma=0$, in particular applying when $\left.F O C_{\gamma}\right|_{\gamma=0, \tau \text { internal }}<0$, hence $\omega<\frac{y^{P}}{y^{R}}$ (see inequalities in 33); or ii) $\gamma \in(0,1)$, applying when $\left.F O C_{\gamma}\right|_{\gamma=0, \tau \text { internal }}>0$, then $\frac{y^{P}}{y^{R}}<\omega<1$. We now separate the analysis in sub-case $i$ ) and sub-case $i i$ ).

Sub-case $i$ ). When $\omega<\frac{y^{P}}{y^{R}}$, the political equilibrium is characterized by $\tau$ internal and $\gamma=0$. The actual value of $\tau$ solving the problem can be found simply imposing $\gamma=0$ in the $F O C_{\tau}$ and solving for $F O C_{\tau}=0$. This gives:

$$
F O C_{\tau}: \frac{-(\omega+1)}{(1-\tau)}+\frac{(\omega+1) \xi}{\tau}-d\left(\ln A^{H}-\ln A^{L}\right)(1-\omega)=0
$$


When $d=0, \tau=\frac{\xi}{1+\xi}$; on the other hand, given that $\frac{\partial F O C_{\tau}}{\partial \tau}<0$, when $d>0$ the optimal $\tau$ is lower than $\frac{\xi}{1+\xi}$. More specifically, it is given by:

$$
\begin{aligned}
\tau= & \frac{1}{2 S(1-\omega)} \cdot[(\omega+1)(1+\xi)+S(1-\omega) \\
& \left.-\sqrt{((\omega+1)(1+\xi)+S(1-\omega))^{2}-4 S(1-\omega)(\omega+1) \xi}\right]
\end{aligned}
$$

where $S=d\left(\ln A^{H}-\ln A^{L}\right)$. (Since in this sub-case $\gamma=0$, equation 36 has also been used to draw the graph of $\tau(1-\gamma)$ in Fig. 2 when $\left.\omega<\frac{y^{P}}{y^{R}}\right)$.

Sub-case ii). When $\frac{y^{P}}{y^{R}}<\omega<1$, the equilibrium is with both $\gamma$ and $\tau$ internal. Hence, both $F O C_{\tau}$ and $F O C_{\gamma}$ must equal 0, namely:

$$
\begin{aligned}
F O C_{\tau}: & \frac{\tau \omega\left(-y^{P}+\gamma \bar{y}\right)}{(1-\tau) y^{P}+\gamma \tau \bar{y}}+\frac{\tau\left(-y^{R}+\gamma \bar{y}\right)}{(1-\tau) y^{R}+\gamma \tau \bar{y}}=-(\omega+1) \xi \\
& +d(1-\gamma) \tau(1-\omega)\left(\ln A^{H}-\ln A^{L}\right) \\
F O C_{\gamma}: \quad & -\frac{(1-\gamma) \omega \tau \bar{y}}{(1-\tau) y^{P}+\gamma \tau \bar{y}}-\frac{(1-\gamma) \tau \bar{y}}{(1-\tau) y^{P}+\gamma \tau \bar{y}}=-(\omega+1) \xi \\
+ & d(1-\gamma) \tau(1-\omega)\left(\ln A^{H}-\ln A^{L}\right)
\end{aligned}
$$

Substituting gives:

$\frac{\tau \omega\left(-y^{P}+\gamma \bar{y}\right)}{(1-\tau) y^{P}+\gamma \tau \bar{y}}+\frac{\tau\left(-y^{R}+\gamma \bar{y}\right)}{(1-\tau) y^{R}+\gamma \tau \bar{y}}=-\frac{(1-\gamma) \omega \tau \bar{y}}{(1-\tau) y^{P}+\gamma \tau \bar{y}}-\frac{(1-\gamma) \tau \bar{y}}{(1-\tau) y^{P}+\gamma \tau \bar{y}}$

and after few manipulations:

$$
\frac{\omega}{(1-\tau) y^{P}+\gamma \tau \bar{y}}=\frac{1}{(1-\tau) y^{R}+\gamma \tau \bar{y}}
$$

Substituting in $F O C_{\tau}$ and $F O C_{\gamma}$, one obtains:

$$
\begin{aligned}
\tau \gamma & =\frac{(1-\tau) \cdot\left(\omega y^{R}-y^{P}\right)}{\bar{y}(1-\omega)} \\
\tau(1-\gamma) & =\frac{\xi 2 \bar{y}}{2 \bar{y}(1+\xi)+S(1-\tau)\left(y^{R}-y^{P}\right)}
\end{aligned}
$$

(where $S=d\left(\ln A^{H}-\ln A^{L}\right)$ ) .

Expressions (39) and (40) can be studied as functions of the optimal $\tau$ and of the other parameters. In particular, after few more manipulations one obtains a quadratic equation for $\tau$ :

$$
\begin{aligned}
h(\tau)= & -\tau^{2} S\left(y^{R}-y^{P}\right)^{2} 0.5(\omega+1) \\
& +\tau\left[\left(y^{R}-y^{P}\right)\left[(1+\xi) \bar{y}(1+\omega)+S\left(\left(\bar{y}(1-\omega)+2\left(\omega y^{R}-y^{P}\right)\right)\right]\right]\right. \\
& -\xi \bar{y}(\omega+1)\left(y^{R}-y^{P}\right)-\left(\omega y^{R}-y^{P}\right)\left(2 \bar{y}+S\left(y^{R}-y^{P}\right)\right)
\end{aligned}
$$

Regarding this function we note the following: 
1. $h(0)<0$ and $h(1)>0$ : hence the function has a single root (the optimal $\left.\tau^{*}\right)$ in the interval $\tau \in(0,1)$; in addition, at $\tau^{*}, \partial h\left(\tau^{*}\right) / \partial \tau>0$.

2. Further, it is possible to show that at $\tau^{*}: \partial h\left(\tau^{*}\right) / \partial \omega<0, \partial h\left(\tau^{*}\right) / \partial d>$ 0 , and $\partial h\left(\tau^{*}\right) / \partial \xi<0$. Since $h(\cdot)$ is increasing at $\tau^{*}$, the signs of the above derivatives imply, in the order, that: $\partial \tau^{*} / \partial \omega>0, \partial \tau^{*} / \partial d<0$, and $\partial \tau^{*} / \partial \xi>0$.

3. From equations (39) and (40) one can then obtain the signs for the derivatives:

$$
\begin{array}{lll}
\frac{\partial \tau \gamma}{\partial \omega}=\frac{\partial \tau}{\partial \omega}\left[1-\frac{S\left(y^{R}-y^{P}\right)}{\left[2 \bar{y}(1+\xi)+S(1-\tau)\left(y^{R}-y^{P}\right)\right]^{2}}\right]>0 & \frac{\partial \tau(1-\gamma)}{\partial \omega}=\frac{S\left(y^{R}-y^{P}\right)}{\left[2 \bar{y}(1+\xi)+S(1-\tau)\left(y^{R}-y^{P}\right)\right]^{2}}>0 \\
\frac{\partial \tau \gamma}{\partial d}=-\frac{\left(\omega y^{R}-y^{P}\right)}{\bar{y}(1-\omega)} \frac{\partial \tau}{\partial d}>0 & \frac{\partial \tau(1-\gamma)}{\partial d}=\frac{\partial \tau}{\partial d}\left[1-\frac{\left(\omega y^{R}-y^{P}\right)}{\bar{y}(1-\omega)}\right]<0 \\
\frac{\partial \tau \gamma}{\partial \xi}=-\frac{\left(\omega \bar{R}^{R}-y^{P}\right)}{\bar{y}(1-\omega)} \frac{\partial \tau}{\partial \xi}<0 & \frac{\partial \tau(1-\gamma)}{\partial \xi}=\frac{\partial \tau}{\partial \xi}\left[1-\frac{\left(\omega y^{R}-y^{P}\right)}{\bar{y}(1-\omega)}\right]>0
\end{array}
$$

which are used to draw the solid lines in Fig. 2 when $\frac{y^{P}}{y^{R}}<\omega<1$ (and $d>0)$.

Alternatively, the same predictions can be obtained studying the explicit forms for $\tau \gamma$ and $\tau(1-\gamma)$, which can also be obtained from equations (39) and (40). In particular, after few manipulations, one can obtain the following quadratic equations for $\tau \gamma$ and $\tau(1-\gamma)$, respectively:

$$
\begin{aligned}
0= & -(\tau \gamma)^{2} S(1-\omega)\left(y^{R}-y^{P}\right)\left[\left(\omega y^{R}-y^{P}\right)+(1-\omega) \bar{y}\right] \\
& -\tau \gamma\left(\omega y^{R}-y^{P}\right)\left(y^{R}-y^{P}\right)[(1+\xi)(\omega+1)-S(1-\omega)] \\
& +2\left(\omega y^{R}-y^{P}\right)^{2} \\
0= & (\tau(1-\gamma))^{2} S(1-\omega)-\tau(1-\gamma)[(1+\xi)(1+\omega)+S(1-\omega)] \\
& +\xi(1+\omega)
\end{aligned}
$$

Regarding the latter equation for $\tau(1-\gamma)$ also notice that since it does not depend on the pair $\left(y^{R}, y^{P}\right)$, but only on the parameters, it is timeinvariant. (Indeed, equation 42 delivers for $\tau(1-\gamma)$ the same root as both equation 35 - holding when the optimal solution is with $\tau=1-$, and equation 36 - holding when in the optimal solution $\gamma=0$ ). Finally, also notice that when $d=0$ (hence $S=0$ ), equations (41) and (42) give:

$$
\begin{gathered}
\tau \gamma=\frac{2\left(\omega y^{R}-y^{P}\right)}{2\left(\omega y^{R}-y^{P}\right)+(\omega+1) \xi\left(y^{R}-y^{P}\right)+\left(y^{R}+y^{P}\right)(1-\omega)} \\
\tau(1-\gamma)=\frac{\xi}{1+\xi}
\end{gathered}
$$

which are used to draw the dotted lines in Fig. 2. 


\section{Proof of Proposition 2 .}

Substitute from Proposition 1 the political equilibrium values of $e_{t}^{J}$ in equation (17) for the different time-invariant $\omega^{J}$. For example, for $\omega^{N}=1$, $e_{t}^{N}=\frac{\xi}{1+\xi} \bar{y}_{t}^{N}$ so that $\bar{y}_{t+1}^{N}=0.5\left(A^{L}+A^{H}\right)\left(\frac{\xi}{1+\xi}\right)^{\xi}\left(\bar{y}_{t}^{N}\right)^{\xi+\delta}$, and $B^{N}=$ $0.5\left(A^{L}+A^{H}\right)\left(\frac{\xi}{1+\xi}\right)^{\xi}$ in equation (18). Similar substitutions when $\omega^{P}>1$ and $\omega^{R}<1$ imply $B^{P}>B^{N}>B^{R}$. The rest of the Proposition follows from basic properties of difference equations. (See also Fig. 3).

\section{Proof of Proposition 3}

Substitute for the generic time-invariant $\frac{e_{t}}{\bar{y}_{t}}$ of equation (13), the specific time-invariant $\frac{e_{t}^{J}}{y_{t}^{J}}=\left(1-\gamma^{J}\right) \tau^{J}$ derived from Proposition 1 under regimes $J=N, P, R$.

\section{Proof of Proposition 4}

Directly from: i) Proposition 2 showing that, under all possible combinations of $\xi+\delta$ (whether greater, lower or equal to 1 ), then $\frac{\bar{y}_{t}^{P}}{\bar{y}_{t-1}^{P}}>\frac{\bar{y}_{t}^{N}}{\bar{y}_{t-1}^{N}}>\frac{\bar{y}_{t}^{R}}{\bar{y}_{t-1}^{R}}$ for at least some $t$ (otherwise they may be equal); ii) Proposition 3 indicating that $\bar{\alpha}_{t+1}^{P}>\bar{\alpha}_{t+1}^{N}>\bar{\alpha}_{t+1}^{R}$ at all $t=1,2, \ldots$; iii) equation (20) for the evolution of $I_{t+1}^{J}$.

\section{Proof of Proposition 5}

From Equation (12) and Proposition (1). 


\section{CESifo Working Paper Series}

(for full list see www.cesifo-group.de)

1872 Hans Gersbach and Bernhard Pachl, Cake Division by Majority Decision, December 2006

1873 Gunther Schnabl, The Evolution of the East Asian Currency Baskets - Still Undisclosed and Changing, December 2006

1874 Horst Raff and Michael J. Ryan, Firm-Specific Characteristics and the Timing of Foreign Direct Investment Projects, December 2006

1875 Jukka Pirttilä and Håkan Selin, How Successful is the Dual Income Tax? Evidence from the Finnish Tax Reform of 1993, December 2006

1876 Agnieszka Stążka, Sources of Real Exchange Rate Fluctuations in Central and Eastern Europe - Temporary or Permanent?, December 2006

1877 Xavier Calsamiglia, Teresa Garcia-Milà and Therese J. McGuire, Why do Differences in the Degree of Fiscal Decentralization Endure?, December 2006

1878 Natacha Gilson, How to be Well Shod to Absorb Shocks? Shock Synchronization and Joining the Euro Zone, December 2006

1879 Scott Alan Carson, Modern Health Standards for Peoples of the Past: Biological Conditions by Race in the American South, 1873 - 1919, December 2006

1880 Peter Huber, Michael Pfaffermayr and Yvonne Wolfmayr, Are there Border Effects in the EU Wage Function?, December 2006

1881 Harry Flam and Håkan Nordström, Euro Effects on the Intensive and Extensive Margins of Trade, December 2006

1882 Panu Poutvaara and Mikael Priks, Hooliganism in the Shadow of the 9/11 Terrorist Attack and the Tsunami: Do Police Reduce Group Violence?, December 2006

1883 Ruud A. de Mooij and Gaëtan Nicodème, Corporate Tax Policy, Entrepreneurship and Incorporation in the EU, December 2006

1884 Johannes Becker and Clemens Fuest, Corporate Tax Policy and International Mergers and Acquisitions - Is the Tax Exemption System Superior?, January 2007

1885 Momi Dahan and Udi Nisan, The Effect of Benefits Level on Take-up Rates: Evidence from a Natural Experiment, January 2007

1886 José García-Solanes, Francisco I. Sancho-Portero and Fernando Torrejón-Flores, Beyond the Salassa-Samuelson Effect in some New Member States of the European Union, January 2007 
1887 Peter Egger, Wolfgang Eggert and Hannes Winner, Saving Taxes Through Foreign Plant Ownership, January 2007

1888 Timothy J. Goodspeed and Andrew Haughwout, On the Optimal Design of Disaster Insurance in a Federation, January 2007

1889 Wim Groot, Henriëtte Maassen van den Brink and Bernard van Praag, The Compensating Income Variation of Social Capital, January 2007

1890 Bas Jacobs, Ruud A. de Mooij and Kees Folmer, Analyzing a Flat Income Tax in the Netherlands, January 2007

1891 Hans Jarle Kind, Guttorm Schjelderup and Frank Stähler, Newspapers and Advertising: The Effects of Ad-Valorem Taxation under Duopoly, January 2007

1892 Erkki Koskela and Rune Stenbacka, Equilibrium Unemployment with Outsourcing under Labour Market Imperfections, January 2007

1893 Maarten Bosker, Steven Brakman, Harry Garretsen, Herman de Jong and Marc Schramm, The Development of Cities in Italy 1300 - 1861, January 2007

1894 Michel Beine, Oscar Bernal, Jean-Yves Gnabo and Christelle Lecourt, Intervention Policy of the BoJ: A Unified Approach, January 2007

1895 Robert S. Chirinko and Daniel J. Wilson, State Investment Tax Incentives: A Zero-Sum Game?, January 2007

1896 Theo S. Eicher and Oliver Roehn, Sources of the German Productivity Demise Tracing the Effects of Industry-Level ICT Investment, January 2007

1897 Helge Berger, Volker Nitsch and Tonny Lybek, Central Bank Boards around the World: Why does Membership Size Differ?, January 2007

1898 Gabriel Felbermayr and Wilhelm Kohler, Does WTO Membership Make a Difference at the Extensive Margin of World Trade?, January 2007

1899 Benno Torgler and Friedrich Schneider, The Impact of Tax Morale and Institutional Quality on the Shadow Economy, January 2007

1900 Tomer Blumkin and Efraim Sadka, On the Desirability of Taxing Charitable Contributions, January 2007

1901 Frederick van der Ploeg and Reinhilde Veugelers, Higher Education Reform and the Renewed Lisbon Strategy: Role of Member States and the European Commission, January 2007

1902 John Lewis, Hitting and Hoping? Meeting the Exchange Rate and Inflation Criteria during a Period of Nominal Convergence, January 2007 
1903 Torben M. Andersen, The Scandinavian Model - Prospects and Challenges, January 2007

1904 Stephane Dees, Sean Holly, M. Hashem Pesaran and L. Vanessa Smith, Long Run Macroeconomic Relations in the Global Economy, January 2007

1905 Richard Jong-A-Pin and Jakob De Haan, Political Regime Change, Economic Reform and Growth Accelerations, January 2007

1906 Sascha O. Becker and Peter H. Egger, Endogenous Product versus Process Innovation and a Firm's Propensity to Export, February 2007

1907 Theo S. Eicher, Chris Papageorgiou and Oliver Roehn, Unraveling the Fortunates of the Fortunate: An Iterative Bayesian Model Averaging (IBMA) Approach, February 2007

1908 Liliana E. Pezzin, Robert A. Pollak and Barbara S. Schone, Efficiency in Family Bargaining: Living Arrangements and Caregiving Decisions of Adult Children and Disabled Elderly Parents, February 2007

1909 Christian Keuschnigg and Soren Bo Nielsen, Self-Selection and Advice in Venture Capital Finance, February 2007

1910 Rune Jansen Hagen and Gaute Torsvik, Irreversible Investments, Dynamic Inconsistency and Policy Convergence, February 2007

1911 Eric A. Hanushek and Ludger Woessmann, The Role of School Improvement in Economic Development, February 2007

1912 Bernard M. S. van Praag, Perspectives from the Happiness Literature and the Role of New Instruments for Policy Analysis, February 2007

1913 Volker Grossmann and Thomas M. Steger, Growth, Development, and Technological Change, February 2007

1914 Margarita Katsimi and Thomas Moutos, Human Capital and the Feldstein-Horioka Puzzle, February 2007

1915 Oliver Roehn, Theo S. Eicher and Thomas Strobel, The Ifo Industry Growth Accounting Database, February 2007

1916 Ian Babetskii, Aggregate Wage Flexibility in Selected New EU Member States, February 2007

1917 Burkhard Heer, Alfred Maussner and Paul D. McNelis, The Money-Age Distribution: Empirical Facts and Limited Monetary Models, February 2007

1918 Yin-Wong Cheung, Menzie D. Chinn and Eijii Fujii, The Overvaluation of Renminbi Undervaluation, February 2007 
1919 Jim Malley, Apostolis Philippopoulos and Ulrich Woitek, To React or Not? Fiscal Policy, Volatility and Welfare in the EU-3, February 2007

1920 Mattias Polborn, Competing for Recognition through Public Good Provision, February 2007

1921 Lars P. Feld and Benno Torgler, Tax Morale after the Reunification of Germany: Results from a Quasi-Natural Experiment, February 2007

1922 Robert S. Chirinko and Huntley Schaller, Fundamentals, Misvaluation, and Investment: The Real Story, February 2007

1923 Benno Torgler and Friedrich Schneider, Shadow Economy, Tax Morale, Governance and Institutional Quality: A Panel Analysis, February 2007

1924 Adrian Pagan and M. Hashem Pesaran, On Econometric Analysis of Structural Systems with Permanent and Transitory Shocks and Exogenous Variables, February 2007

1925 Hans-Werner Sinn, The Welfare State and the Forces of Globalization, February 2007

1926 Michael Smart, Raising Taxes through Equalization, February 2007

1927 Øystein Foros, Kåre P. Hagen and Hans Jarle Kind, Price-Dependent Profit Sharing as an Escape from the Bertrand Paradox, February 2007

1928 Balázs Égert, Kirsten Lommatzsch and Amina Lahrèche-Révil, Real Exchange Rates in Small Open OECD and Transition Economies: Comparing Apples with Oranges?, February 2007

1929 Aleksander Berentsen and Cyril Monnet, Monetary Policy in a Channel System, February 2007

1930 Wolfgang Ochel, The Free Movement of Inactive Citizens in the EU - A Challenge for the European Welfare State?, February 2007

1931 James K. Hammitt and Nicolas Treich, Statistical vs. Identified Lives in Benefit-Cost Analysis, February 2007

1932 Wilhelm Kohler, The Bazaar Effect, Unbundling of Comparative Advantage, and Migration, February 2007

1933 Karsten Staehr, Fiscal Policies and Business Cycles in an Enlarged Euro Area, February 2007

1934 Michele Bernasconi and Paola Profeta, Redistribution or Education? The Political Economy of the Social Race, March 2007 